\title{
Jasmonic Acid-Dependent MYC Transcription Factors Bind to a Tandem G-Box Motif in the YUCCA8 and YUCCA9 Promoters to Regulate Biotic Stress Responses
}

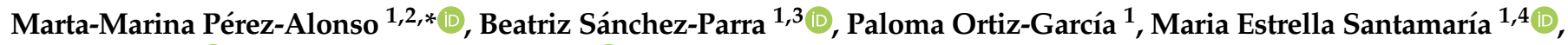 \\ Isabel Díaz ${ }^{1,4}$ (D) and Stephan Pollmann ${ }^{1,4, *(D)}$ \\ 1 Centro de Biotecnología y Genómica de Plantas, Instituto Nacional de Investigación y Tecnología Agraria y \\ Alimentación (INIA), Universidad Politécnica de Madrid (UPM), 28223 Pozuelo de Alarcón, Spain; \\ beatriz.sanchez-parra@uni-graz.at (B.S.-P.); p.ortiz@upm.es (P.O.-G.); me.santamaria@upm.es (M.E.S.); \\ i.diaz@upm.es (I.D.) \\ 2 Department of Forest Genetics and Plant Physiology, Umeå Plant Sciences Centre (UPSC), \\ Swedish University of Agricultural Science, 90183 Umeå, Sweden \\ 3 Institut für Biologie, Bereich Pflanzenwissenschaften, Karl-Franzens Universität Graz, 8010 Graz, Austria \\ 4 Departamento de Biotecnología-Biología Vegetal, Escuela Técnica Superior de Ingeniería Agronómica, \\ Alimentaria y de Biosistemas, Universidad Politécnica de Madrid (UPM), 28040 Madrid, Spain \\ * Correspondence: marta.perez.alonso@slu.se (M.-M.P.-A.); stephan.pollmann@upm.es (S.P.); \\ Tel.: +34-910679183 (S.P.)
}

check for updates

Citation: Pérez-Alonso, M.-M.; Sánchez-Parra, B.; Ortiz-García, P.; Santamaría, M.E.; Díaz, I.; Pollmann, S. Jasmonic Acid-Dependent MYC Transcription Factors Bind to a Tandem G-Box Motif in the YUCCA8 and YUCCA9 Promoters to Regulate Biotic Stress Responses. Int. J. Mol. Sci. 2021, 22, 9768. https:// doi.org/10.3390/ijms22189768

Academic Editor: Ryszard Lobinski

Received: 2 July 2021

Accepted: 7 September 2021

Published: 9 September 2021

Publisher's Note: MDPI stays neutral with regard to jurisdictional claims in published maps and institutional affiliations.

Copyright: (c) 2021 by the authors. Licensee MDPI, Basel, Switzerland. This article is an open access article distributed under the terms and conditions of the Creative Commons Attribution (CC BY) license (https:/ / creativecommons.org/licenses/by/ $4.0 /)$.

\begin{abstract}
The indole-3-pyruvic acid pathway is the main route for auxin biosynthesis in higher plants. Tryptophan aminotransferases (TAA1/TAR) and members of the YUCCA family of flavin-containing monooxygenases catalyze the conversion of L-tryptophan via indole-3-pyruvic acid to indole-3-acetic acid (IAA). It has been described that jasmonic acid (JA) locally produced in response to mechanical wounding triggers the de novo formation of IAA through the induction of two YUCCA genes, YUC8 and YUC9. Here, we report the direct involvement of a small number of basic helix-loop-helix transcription factors of the MYC family in this process. We show that the JA-mediated regulation of the expression of the YUC8 and YUC9 genes depends on the abundance of MYC2, MYC3, and MYC4. In support of this observation, seedlings of myc knockout mutants displayed a strongly reduced response to JA-mediated IAA formation. Furthermore, transactivation assays provided experimental evidence for the binding of MYC transcription factors to a particular tandem G-box motif abundant in the promoter regions of YUC8 and YUC9, but not in the promoters of the other YUCCA isogenes. Moreover, we demonstrate that plants that constitutively overexpress YUC8 and YUC9 show less damage after spider mite infestation, thereby underlining the role of auxin in plant responses to biotic stress signals.
\end{abstract}

Keywords: Arabidopsis thaliana; indole-3-acetic acid; jasmonic acid; plant hormone crosstalk; transcriptional regulation; wound response; biotic stress; growth-defense trade-off

\section{Introduction}

Since its discovery in the 1930s [1-3], many studies have firmly demonstrated that auxins govern virtually every aspect of plant life related to growth and development, e.g., cell elongation, tropisms, apical dominance, initiation of lateral and adventitious root growth, senescence, and flowering [4-6]. However, despite the great importance of auxin for plant development, the role of auxin in plant defense is still not fully understood. Several pieces of evidence indicate that indole-3-acetic acid (IAA), the major auxin in plants, exerts a negative role in resistance to plant stress, and that investing in plant growth imposes a penalty on plant defense, and vice versa [7-10] - a phenomenon referred to as the growth-defense trade-off [11]. Consistent with these affirmations, activation of IAA-mediated stem elongation in response to light has been described to make Arabidopsis 
thaliana and Chenopodium album plants more susceptible to different pathogens, such as the bacteria Pseudomonas syringae or larvae of the beet armyworm Spodoptera exigua [12,13]. Similarly, Mutka and co-workers [14] showed that an increase in endogenous IAA levels in Arabidopsis decreases plant tolerance to P. syringae. On the contrary, another series of studies suggests that auxin can positively influence plant tolerance. Here, the auxin signaling component AUXIN RESPONSE FACTOR 3 (ARF3) has been reported to control the formation of leaf trichomes, considered a direct defense mechanism against predators [15,16]. In addition, analyses carried out using the Arabidopsis auxin reporter line DR5::GUS showed that mechanical wounding stimulates IAA signaling in neighboring unwounded plants [17], suggesting an indirect defense mechanism that allows plants to prepare for a possible imminent attack. With the aim of adding to this knowledge, we intend not only to shed light on the implication of auxin in plant biotic stress responses, but also to provide new molecular targets that contribute to the plant growth-defense trade-off phenomenon.

In the context of plant stress responses, jasmonates play a prominent role. They are lipid-derived hormones comprising jasmonic acid (JA) and several derivatives of JA [18]. These molecules play an essential role in counteracting abiotic and biotic stress responses, such as pathogen and herbivore attacks [19-21]. Upon recognition of stress, the production of the bioactive JA, jasmonoyl-L-isoleucine (JA-Ile) is stimulated and perceived by the CORONATINE INSENSITIVE 1 (COI1) protein. This enables the Skp-Cullin 1-Fbox (SCF) E3 ligase complex to interact with and ubiquitinate specific repressor proteins known as JASMONATE ZIM DOMAIN proteins (JAZ). Degradation of JAZs by the $26 \mathrm{~S}$ proteasome releases the MYC family of basic helix-loop-helix (bHLH) transcription factors from repression, which subsequently triggers the expression of different subsets of genes responsive to JA $[11,22,23]$.

In recent years, a wide range of links between the JA and auxin signaling pathways have been reported. For example, JA has been shown to negatively affect primary root growth in A. thaliana through transcriptional repression of PLETHORA genes, namely PLT1 and PLT2, which are known as essential transcription factors that control the specification and maintenance of the auxin-regulated root meristem [24]. More recent work has described a crosstalk model in which wound-inducible amidohydrolases contribute to the cellular regulation of JA and auxin levels to coordinate stress responses by controlling JAand IAA-amino acid conjugate contents [16]. On the contrary, a series of publications emphasized that JA exerts a direct stimulating effect on various phases of auxin biosynthesis. Dombrecht et al. [25] reported the JA-associated transcription factor MYC2 to control the formation of auxin biosynthesis precursors as well as auxin-related defense compounds, including indole glucosinolates. Furthermore, JA has been demonstrated to promote auxin de novo-biosynthesis through the transcriptional activation of two anthranilate synthase genes, ASA1 and ASB1, resulting in elevated levels of L-tryptophan and, therefore, increased precursor availability for auxin biosynthesis [26]. Hentrich et al. [27] have reported a more direct impact on auxin biosynthesis. The authors provided evidence for the JAdependent transcriptional activation of two Arabidopsis YUCCA genes, YUC8 and YUC9. Intriguingly, YUCCA enzymes are considered key players in general IAA biosynthesis, along with tryptophan aminotransferases [28-31]. Importantly, the gene expression studies presented by Hentrich et al. [27] showed that the transcriptional response of YUC8 and YUC9 to the treatment with different oxylipins, including methyl jasmonate (MeJA) and its precursor 12-oxo-phytodienoic acid (OPDA), is almost entirely impaired in the coil mutant background. Based on this experiment, it was speculated that the transcriptional regulation of YUC8 and YUC9 depends on the COI-JAZ-MYC signaling module.

In this work, we show that the Arabidopsis transcription factor MYC2, and its closest homologues MYC3 and MYC4 [32], play a direct role in the regulation of auxin biosynthesis through the control of the expression of the YUC8 and YUC9 genes. We demonstrate that different $m y c$ knockout mutants display a significant reduction not only in JA-mediated IAA production, but also in the accumulation of $Y U C 8$ and $Y U C 9$ transcripts. Moreover, our transient transactivation analyses in Nicotiana benthamiana and Arabidopsis protoplasts 
clearly demonstrate that MYC2, MYC3, and MYC4 bind to a specific tandem G-box motif abundant in the promoter regions of $Y U C 8$ and $Y U C 9$, which is absent in the promoters of the other YUCCA genes. Finally, YUC8 and YUC9 promoter-reporter lines and mutants have been subjected to biotic stress conditions by applying the two-spotted spider mite Tetranychus urticae to their leaves, which provided compelling evidence that the overexpression of the YUC9 gene rendered the mutant plants more resistant to the herbivore predators. Taken together, our results provide evidence for a signal transduction mechanism that employs the COI-JAZ-MYC module to fine-tune the expression of auxin biosynthesis-related genes in response to wounding and resistance to phytophagous mites.

\section{Results}

\subsection{MYC2, MYC3, and MYC4 Trigger Auxin Formation after JA Treatment}

First, we investigated whether MYC transcription factors are directly involved in de novo IAA synthesis. To this end, we quantified the endogenous IAA levels in $A$. thaliana wild-type seedlings (Col-0), as well as different myc mutants, four hours after the treatment with $50 \mu \mathrm{M}$ MeJA by gas chromatography-tandem mass spectrometry (GC-MS/MS) (Figure 1). Confirming previous observations [27], the application of MeJA to WT seedlings translated into a more than 4.5 -fold increased IAA formation relative to mock-treated control seedlings $(0.5 \% \mathrm{MeOH}(v / v))$. On the contrary, there was no detectable stimulation of IAA production in myc single mutants, the $m y c 2 / m y c 3$ and $m y c 2 / m y c 4$ double mutants, and the $m y c 2 / m y c 3 / m y c 4$ triple mutant upon MeJA-treatment. Interestingly, we observed a pronounced reduction in IAA accumulation in the myc triple mutant $(0.5$-fold) when compared with the respective mock-treated control. This observation prompts us to think that the three MYCs transcription factors collaborate in the control of JA-mediated IAA accumulation. Remarkably, although all single myc mutants displayed a general tendency of impaired MeJA-mediated IAA formation (no significant differences to the mock-treated controls), myc3/myc4 seedlings exhibited a remaining significant increase in IAA contents in response to the MeJA application. Intriguingly, a recent study demonstrated the overexpression of the GROWTH REGULATING FACTOR (GRF)-INTERACTION FACTOR 1 (GIF1) in the double myc3/myc4 mutant [33] This transcriptional co-activator regulates leaf growth and development together with GRFs, a group of transcription factors that could contribute to the regulation of auxin biosynthesis $[34,35]$. However, with an increase of approximately 3.5 -fold over the corresponding mock-treated myc3/myc4 seedlings, the detected response was still weaker than the one observed for wild-type seedlings.

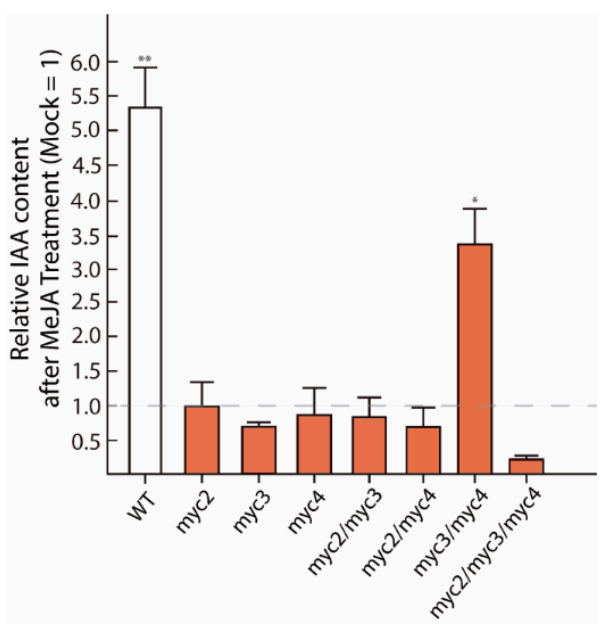

Figure 1. JA-triggered IAA biosynthesis is curtailed in myc mutants. IAA contents were assessed by GC-MS/MS in 10 days-old seedlings treated with either $50 \mu \mathrm{M}$ MeJA or a mock solution $(0.5 \% \mathrm{MeOH}$ $(v / v))$ for $4 \mathrm{~h}$. Stable isotope labelled $\left[{ }^{2} \mathrm{H}_{2}\right]$-IAA was used as internal standard for the absolute quantification of IAA in the samples. To determine the relative IAA-production after MeJA-treatment, 
the IAA contents in the mock treated samples were arbitrarily set to a value of one and the IAA content in MeJA-treated samples was expressed relative to this value. The bars show the mean $\pm \mathrm{SE}$ $(n=3)$. Significant differences between means, comparing mock treated seedlings with the respective treated WT or myc loss-of-function mutant, are indicated with asterisks ${ }^{*} p<0.05,{ }^{* *} p<0.01$; Student's $t$-test).

In summary, the presented results support the idea of an intimate crosstalk between JA signaling and IAA biosynthesis. At the same time, taking the strongest wounding response of MYC2 relative to the other two MYCs into account [32], the obtained data suggest the participation of all tested MYC proteins in the regulation of YUC8/9 gene expression, and point toward a possibly leading role of MYC2 in this process.

\subsection{MeJA-Dependent YUC8 and YUC9 Induction Is Abolished in Myc Loss-of-Function Mutants}

To confirm the role of MYC transcription factors in the transcriptional activation of YUC8 and YUC9, we conducted quantitative reverse transcriptase PCR (qRT-PCR) analyses after seedlings were treated with exogenous MeJA. In accordance with previous results, we observed that YUC8 and YUC9 expression increased 1.3-fold and 8.7-fold in WT seedlings, respectively (Figure 2). In addition, we found that the gene expression of both YUC genes was unaffected by the exogenous application of MeJA in practically all single, double, and triple myc knockout mutants. Surprisingly, in both myc3 and myc2/myc3 the YUC 8 transcript accumulation was slightly activated after $4 \mathrm{~h}$ of MeJA treatment (0.67-fold induction and 1.4-fold induction, respectively) (Figure 2A). Notably, in the myc4 background YUC9 expression was significantly induced after $4 \mathrm{~h}$ of MeJA application (7.8-fold induction) (Figure 2B). Consistent with this observation, Zhang et al. [36] demonstrated a significantly higher JA accumulation in the myc4 mutant after wounding, when compared to wt and the single $m y c 2$ and $m y c 3$ knockout lines. Taken together, these results underpin that MYC2 and MYC4 contribute to MeJA-induced YUC8 transcription. While MYC2 and MYC3 are likely to contribute to the regulation of YUC9 gene expression under this condition. It is noteworthy that we detected no complete loss of YUC8 and YUC9 expression in $m y c 2 / m y c 3 / m y c 4$ (Figure 2A,B). This observation may be interpreted as an indication for a compensatory mechanism to attenuate the absence of JA response in plants or the involvement of other MYC paralogs, such as MYC5, which has recently been reported to contribute to plant defense [37]. However, the transcriptomics analysis of the myc2/myc3/myc4 triple mutant provided no evidence for upregulation of MYC5 gene expression [38].

A

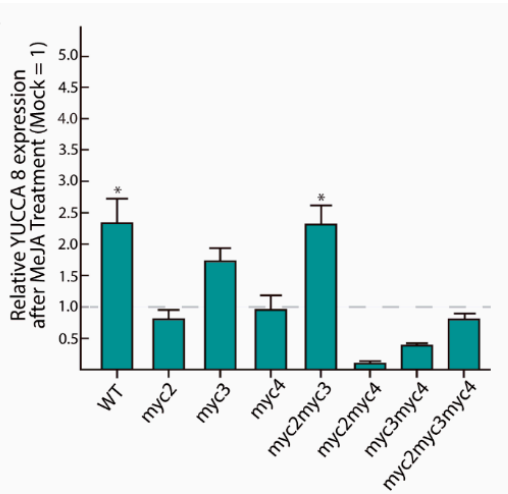

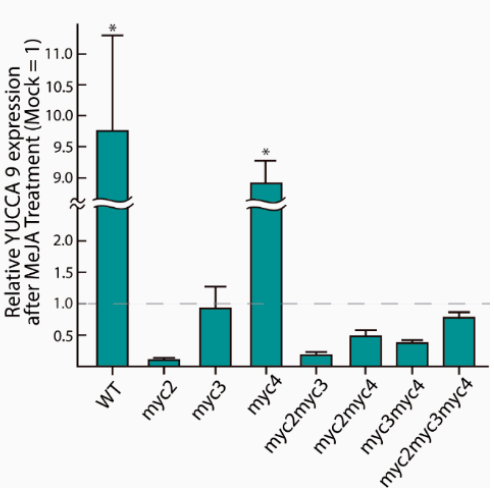

Figure 2. MYC2, MYC3, and MYC4 contribute to the control YUC8 and YUC9 expression in response to MeJA. Depicted is the qRT-PCR analysis of (A) YUC8 and (B) YUC9 expression after MeJAtreatment ( $4 \mathrm{~h}$ and $2 \mathrm{~h}$ for YUC 8 and YUC9, respectively). The transcript levels of YUC 8 and YUC9 are given relative to the reference genes $U B I 10$ and APT1 and normalized using the mock treated seedlings $(0.5 \% \mathrm{MeOH}(v / v))$. The data shown are mean $\pm \mathrm{SE}(n=3)$. We established a two-fold change between the mock treated seedlings and the respective MeJA-treated seedlings as threshold to assume a differential regulation ( ${ }^{*}$ fold-change $\geq 2$ ). 


\subsection{The YUC8 and YUC9 Promoters Contain a Conserved MYC2, MYC3, and MYC4 Binding Motif}

To further investigate the role of MYC2, MYC3, and MYC4 in the transcriptional regulation of $Y U C 8$ and $Y U C 9$, the 3000 bp sequence upstream of the transcription startcodon was retrieved for the eleven A. thaliana YUCCA genes and used to screen for MYC binding motifs, i.e., for the canonical G-box (5'CACGTG-3') and its fifteen described G-box variants [32]. As presented in Figure 3, we noticed that all YUCCA promoters contained a considerable number of JA-responsive elements. Most remarkable, however, was the observation that only the promotors of YUC8 ( YUC8) and YUC9 (pYUC9) contain a particular "tandem" DNA binding motif configuration. This "tandem" consisted in two canonical G-boxes (5'-CACGTG-3'), designated with number 1 in Figure 3, and one G-box variant 9 ( $5^{\prime}$-CACGTC-3') at the nucleotide positions $-535,-555$ and -571 in case of $p Y U C 8$, and -1240 , -1247 and -1272 in $p$ YUC9. Furthermore, we found that the observed "1-9-1" configuration is accompanied by the G-box variant 3 (5'-CATGTG -3') in positions - 140 and -207 of $p$ YUC8 and $p Y U C 9$, respectively.

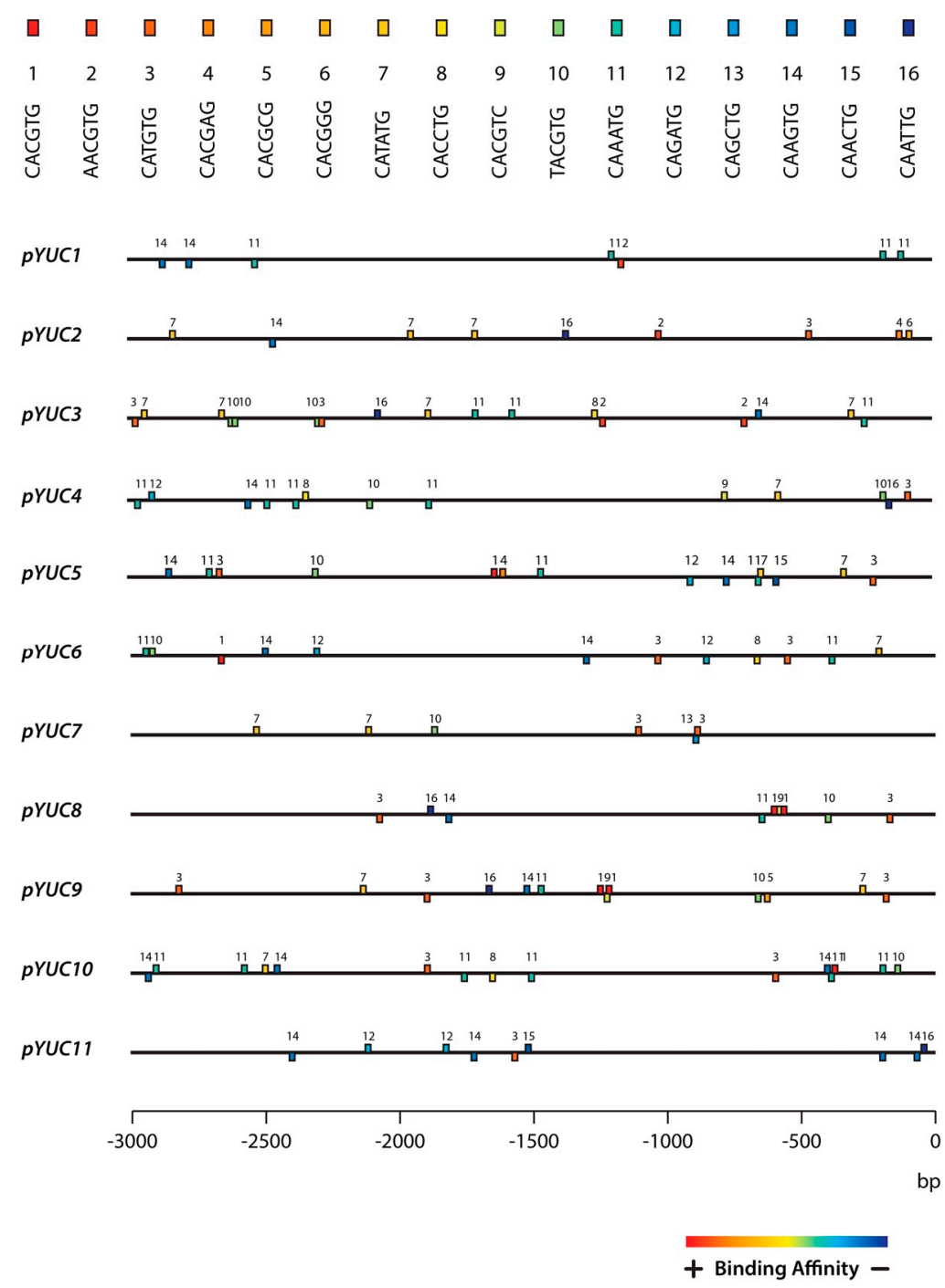

Figure 3. The promoters of YUC8 and YUC9 present a specific G-boxes binding motif configuration. Schematic representation of the distribution of G-box and putative G-box variants in the promoter of Arabidopsis YUCCA genes. The -3000 to -1 promoter region upstream to the transcriptional start codon (ATG) of the eleven YUC family members is shown. All reported G-boxes are color-coded (square) and associated with a specific sequence. Numbers indicate the corresponding G-box nucleotide sequence, with number 1 being the described canonical G-box. Colors indicate different experimental MYC2 binding affinities [32]. 
Notably, the G-box variant 3 was relatively close to a 5'-TATAAA-3' sequence, in positions -153 ( YUC8) and -267 ( YUC9). This sequence has been identified as the consensus TATA-box, a well-known transcriptional enhancer [39]. For this reason, we hypothesized that the observed combination of cis-elements (G-boxes) may be crucial for the transcriptional regulation of YUC8 and YUC9, differentiating them from the other YUC genes.

Intriguingly, our observations were recently partially confirmed by chromatin immunoprecipitation DNA-sequencing (ChIP-seq) assays using JA-treated Col-0 MYC2::MYC2-YPet and Col-0 MYC3::MYC3-YPet seedlings [40]. As can be taken from Figure A1, the AnnoJ genome browser screenshots visualize the binding of MYC2 and MYC3 particular to the promoter of YUC9 and, to a lesser extent, to YUC8. In addition, there might be a less pronounced binding of MYC2 to the G-box \#3 region of YUC2 and YUC5, located close to the transcriptional start-codon.

\subsection{MYC2 Regulates YUC8 and YUC9 Expression through the Interaction with G-Box Elements}

Next, we studied whether the observed cis-regulatory elements are indeed involved in the transcriptional regulation of YUC8 and YUC9. To this end, we performed a transient transactivation effector-reporter experiment in $N$. benthamiana leaves. To set up the effector plasmids, i.e., 35S::MYC2, 35S::MYC3, and 35S::MYC4, the open reading frames from $M Y C 2, M Y C 3$, and MYC4 were independently amplified and fused to the Cauliflower mosaic virus (CaMV) $35 \mathrm{~S}$ promoter (Figure $4 \mathrm{~A}$ ). To prove our hypothesis described above, we generated three reporter constructs for $p Y U C 8$, termed -191::GUS, -3::GUS, and -Ø::GUS, and three promoter constructs for $p Y U C 9$, referred to as -191::GUS, -3::GUS, and - $\varnothing:: G U S$ (Figure 4A). The different truncated promoter fragments for YUC8 or YUC9, containing the tandem DNA motifs (191) or the final cis-acting element (\#3), as well as a promoter segment without any of these regulatory sequences (Ø), were amplified by PCR and cloned into a vector carrying the GUS reporter gene. Subsequently, we investigated the transient GUS activation after Agrobacterium-mediated N. benthaminana leaf infiltration (Figure 4B). Remarkably, the experiment revealed that MYC2, MYC3, and MYC4 are capable of triggering GUS expression in presence of the -191::GUS and -3::GUS constructs of both YUCCA promoters studied, while the corresponding - $\varnothing:: G U S$ constructs served as negative controls. Nonetheless, we observed a faint patchy blue distribution in the -Ø::GUS leaf discs, indicating a very weak background activity of the constructs. In view of this result, we aimed at a quantitative assessment of GUS transactivation (Figure A2). In agreement with the results presented above, we observed that in presence of MYC2, the GUS activity of -191::GUS and -3::GUS samples increased 2-fold and 0.8-fold for the $p$ YUC8 constructs, and 2.3-fold and 1.3-fold for the $p Y U C 9$ constructs, respectively when compared to the negative control (empty vector). Intriguingly, the quantitative analysis indicated that only the $p$ YUC8-191::GUS construct was significantly activated when MYC3 was present. The lack of GUS activity in -3::GUS may indicate that MYC3 does not effectively bind to the 5'-CATGTG-3' regulatory element \#3. Nonetheless, the $p Y U C 9$ results called this interpretation into question, since the fluorometric assay showed significant activation of the GUS activity in -191::GUS (2.5-fold) and -3::GUS (11.5-fold) relative to the negative control. Finally, we detected that only MYC4 activated the pYUC8-3::GUS construct, whereas, GUS activity levels were elevated in both $p$ YUC9-191::GUS and $p$ YUC9-3::GUS, 4.5-fold and 4-fold, respectively in comparison to the negative control (Figure A2). In contrast to MYC2 and MYC3, co-infiltration of N. benthamiana leaf discs with MYC4 resulted in a moderate GUS activity for the $p Y U C 8-\varnothing:: G U S$ construct. The analysis of the YUC8 promoter revealed the presence of the $5^{\prime}$-CAAATG-3' the G-box variant \#11, suggesting that these DNA binding sites could be important in the transcriptional regulation of YUC8 driven by MYC4. Overall, our analyses identified MYC2 as a positive regulator of the auxin biosynthesis-related genes $Y U C 8$ and $Y U C 9$, most probably through its interaction with the promoter G-box "tandem" 1-9-1 and/or the G-box \#3. With respect to the work of Sun et al. [26], the YUC2 gene could also be a MYC2 target in Arabidopsis roots, probably 
through the G-box \#3. In addition, our observations suggest that MYC3 and MYC4 may co-operate to control the expression of YUC8 and YUC9.

To further validate the physical interaction between MYC2 and the YUC8 and YUC9 promoters by an alternative in planta method, we carried out a third experiment in A. thaliana mesophyll protoplasts (Figure 5). Here, constructs analogous to those used for the $N$. benthamiana transient expression assay were utilized. In addition, an empty pBT-10 plasmid was co-transfected with the 35S::MYC2 effector constructs as negative control (Figure 5A). Confirming our previous findings, the relative enzymatic GUS activities showed that, in comparison to the empty vector (named as negative control), MYC2 significantly activated the GUS reporter gene of the $p Y U C 8 / 9-191:: G U S$ and $p Y U C 8 / 9-3:: G U S$ constructs (Figure 5B). Notably, the observed GUS activity for the $p Y U C 9-\varnothing:: G U S$ construct exhibited an increment of approximately 1.5-fold, relative to the negative control. Like in the N. benthamiana transactivation assay; this could be due to the cis-regulatory elements found in the $\varnothing$ promoter fragment (G-box variants 5 (5'-CACGCG-3') and 10 $\left(5^{\prime}\right.$-TACGTG-3')).

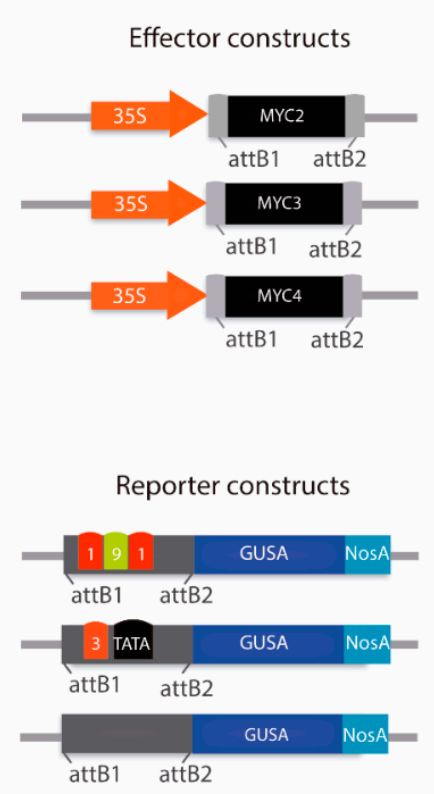

B 191::GUS $\quad 3::$ GUS $\varnothing:: G U S$

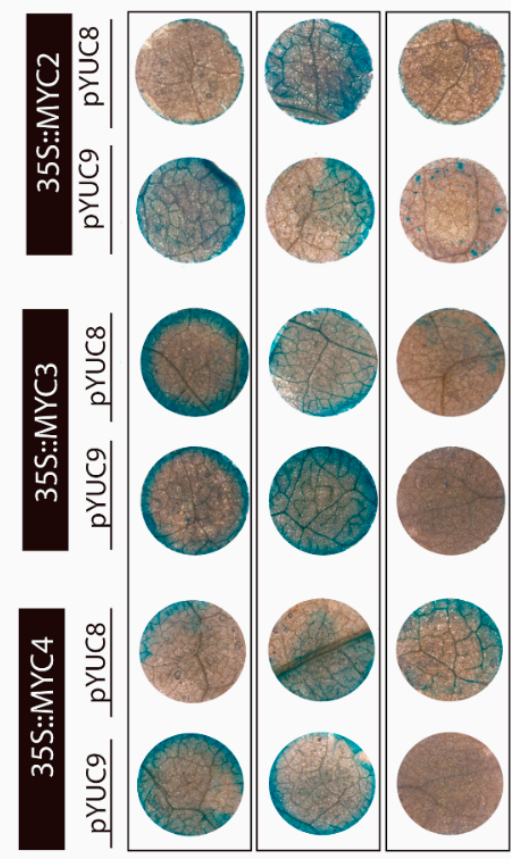

Figure 4. Transactivation of the $p Y U C 8:: G U S$ and $p Y U C 9:: G U S$ by MYC2, MYC3, and MYC4 in agroinfiltrated $N$. benthamiana leaf discs. (A) Schematic representation of the effector and reporter constructs used in the transient expression experiment. The effector constructs contain the CaMV $35 S$ promoter fused to the $M Y C 2, M Y C 3$, and MYC4 ORFs. The reporter constructs contain different combinations of the G-box binding sites found in the YUC8 and YUC9 promoters, i.e., the tandem 1-9-1 (5'-CACGTG-CACGTC-CACGTG-3') - the final cis-regulatory G-box \#3 (5'-CATGTG-3'). Moreover, $\varnothing$ refers to the promoter fragment lacking any of the mentioned DNA binding sites. All reporter constructs were fused to the GUS reporter gene, followed by the NOS terminator cassette. (B) Histochemical GUS staining of $N$. benthamiana leaf discs independently agroinfiltrated with the 35S::MYC2, 35S::MYC3 and 35S::MYC4 constructs, and the reporter constructs -191::GUS and -3::GUS from the $p Y U C 8 / 9$. The $-\varnothing:: G U S$ constructs were used as a negative controls.

Most importantly, our results support the notion that the tested MYC protein in this assay, MYC2 directly binds to the G-box elements found in the YUC8 and YUC9 promoter, thereby controlling their gene expression. 
A

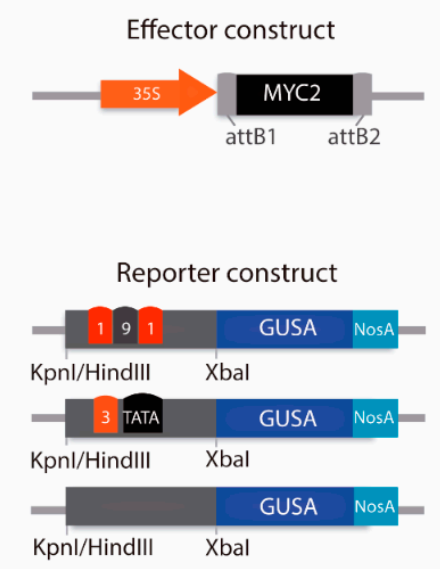

B

\section{S::MYC2}

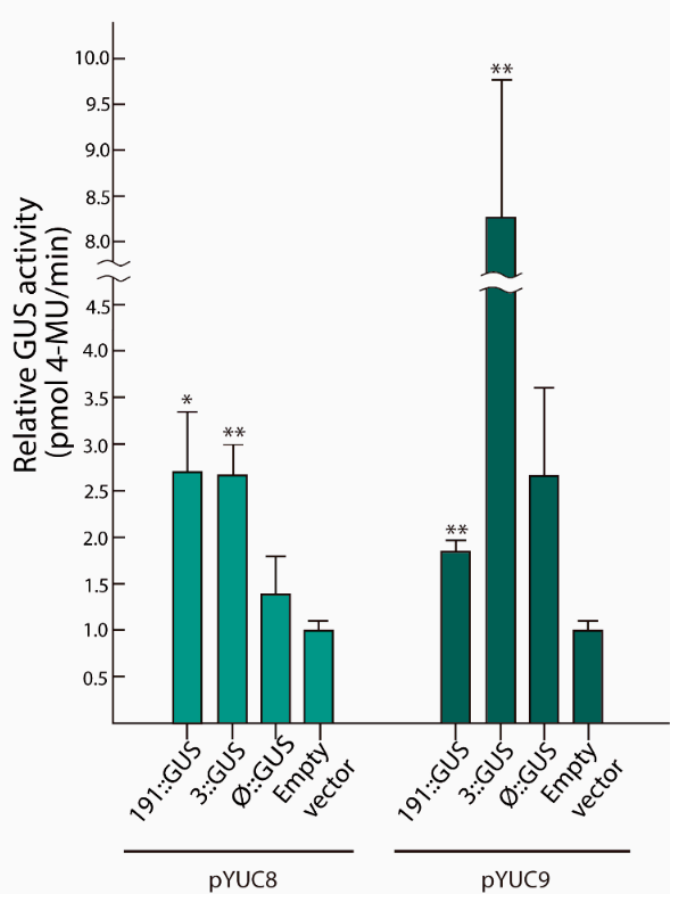

Figure 5. Transcriptional activity assay in A. thaliana mesophyll protoplasts. (A) Schematic representation of the effector constructs 35S::MYC2 and the -191::GUS, -3::GUS and - Ø::GUS reporter constructs used. (B) Fluorometric GUS activity quantification. The empty plasmid was employed as negative control. Here, GUS activity was relativized to the NAN reporter gene activity and normalized to the empty vector. Final GUS activation levels are expressed as pmol 4-methylumelliferone (MU)/min. Values are mean \pm SE. To perform this experiment, three aliquots per protoplast suspension were inspected. Similar results were obtained in two independent experiments. Asterisks indicate Student's $t$-test significant differences $\left({ }^{*} p<0.05,{ }^{* *} p<0.01\right)$.

\subsection{YUC9 Plays a Role in Biotic Stress Responses}

The bHLH transcription factor MYC2 plays a key role in JA-mediated defense responses against herbivores and necrotrophic pathogens [23,41-43]. This prompted us to investigate the activation of YUC8 and YUC9 expression by a phytophagous pest. To this end, three to four weeks-old wild-type plants and the reporter lines $p Y U C 8:: G U S$, pYUC9::GUS, and pAOS::GUS were exposed to the two-spotted spider mite, Tetranychus urticae. Subsequent GUS staining clearly revealed a strong reporter activity for the positive control, the AOS (At5g42650) promoter line, and the YUC9 promoter driven construct (Figure 6A). On the contrary, the absence of visible GUS activity in $p Y U C 8:: G U S$ leaves subjected to T. urticae suggests that $Y U C 8$ is possibly not involved in the defense against pests or that the response of YUC8 is slower than the response of YUC9, which has previously been suggested for oxylipin treatments by Hentrich et al. [27]. In view of this result, we intended to shed light on the biological meaning of MYC2 driven auxin synthesis. To analyze if genetic alterations in YUC9 expression have an influence on the susceptibility of the corresponding plants toward herbivorous predators, WT, YUC9 overexpressing plants (YUC9ox), and the yuc9 mutant (yuc9ko) were tested. Twenty adult female spider mites were placed on single leaves of ten plants from each genotype and allowed to feed for four days. The leaf damage quantification highlighted a preference for adult mites to feed on WT rather than YUC9ox plants. This is displayed by an approximately $40 \%$ lower leaf damage area of YUC9ox compared to WT (Figure 6B). Interestingly, the yuc9ko mutants exhibited a decreased leaf damage area in comparison to WT, but the difference is 
statistically insignificant. Consistent with these observations, the 3,3'-diaminobenzidine (DAB) staining, which indicates the presence of $\mathrm{H}_{2} \mathrm{O}_{2}$, and the trypan blue exclusion test, which gives account on cell viability, determined a visibly higher accumulation of reactive oxygen species (ROS) and cell death in WT and yuc9ko plants in comparison to YUC9ox (Figure A3; Appendix A).

A

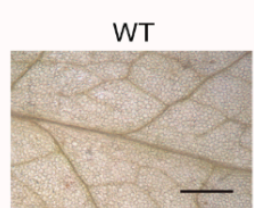
pYUC8::GUS
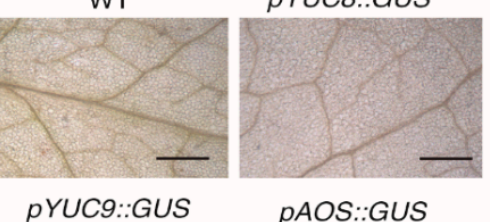

pAOS::GUS
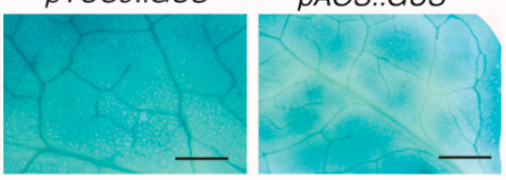

B

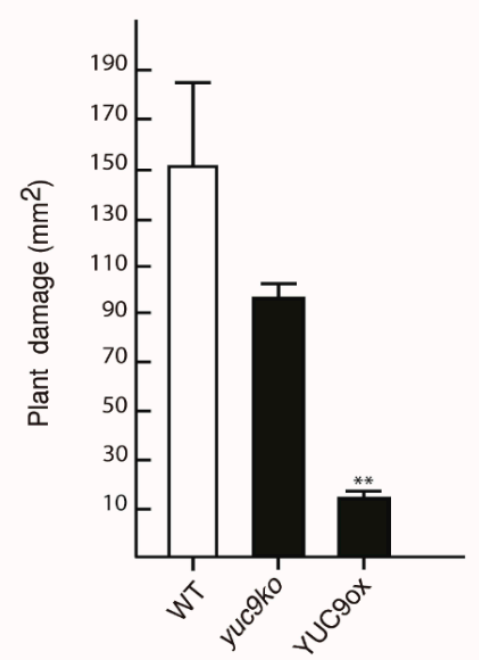

Figure 6. YUC9 activation and plant damage assay after four days of spider mite (Tetranychus urticae) herbivory. (A) Histochemical GUS staining of leaves from wild-type Arabidopsis, pYUC8::GUS, pYUC9::GUS and pAOS::GUS plants, using 20 females from T. urticae per plant $(n=5)$. Scale bar $=50 \mu \mathrm{m}$. (B) Quantification of the total plant damage area (expressed in $\mathrm{mm}^{2}$ ) in WT, yuc9ko and YUC9ox mutant lines. Represented are means \pm SE $(n=5)$. Student's $t$-test: ${ }^{* *} p<0.01$.

\section{Discussion}

The existence of an intimate interplay between JA and IAA is highlighted by the fact that both phytohormones share a conserved signal transduction mechanism [44-46]. In line with this finding, Tiryaki and Staswick [47] demonstrated that depletion of the ubiquitination-related gene AXR1 in Arabidopsis not only confers auxin resistance, but also generates MeJA insensitive mutants. This invited to think that AXR1 may contribute to the perception of both JA and IAA. In addition, evidence has been provided that a point mutation in one subunit forming the SCF-E3 ligase complex of Arabidopsis is enough to significantly reduced the transcript accumulation of JA-related genes and curtail the auxin response [48]. Downstream in the signaling cascade, both hormones cooperate spatiotemporally to regulate flower development and fertility through the action of ARF6 and ARF8 [49]. In rice coleoptiles, asymmetrical growth in response to gravitropism is simultaneously controlled by IAA-JA gradients [50]. On the other hand, crosstalk between JA signaling and IAA biosynthesis pathways has also been disclosed. Mueller et al. [51] and Pauwels et al. [52] independently reported the induction of YUC8 and YUC9 by OPDA and MeJA. Later, Hentrich et al. [27] clearly demonstrated that wound-induced formation of 
MeJA in Col-0 Arabidopsis leaves is sufficient to mediate YUC9 expression. Nevertheless, the molecular mechanism that controls $Y U C 8 / 9$ expression remained largely uncertain.

In our effort to address whether these two auxin biosynthetic genes are direct targets of the JA signaling pathway, we explored whether MYC2, MYC3, and MYC4 are involved in the transcriptional regulation of YUC8 and YUC9. Our GC-MS/MS and qRT-PCR experiments highlighted that JA-dependent IAA production by YUC8 and YUC9 is considerably affected by the presence of the master JA regulator MYC2 (Figures 1 and 2). Our results also disclosed a contribution of MYC3 and MYC4 to MeJA-triggered auxin formation. The latter finding additionally confirms the phylogenetically close relationship of these two bHLH transcription factors with MYC2 (Figure 1). Furthermore, we provide evidence indicating that MYC3 could control the expression of YUC8, while MYC4 is probably involved in the transcriptional regulation of YUC9. However, since the MeJA treatment induced the accumulation of transcripts of both genes in some myc loss-of-function mutants, it may also be possible that alternative transcription factors, like, for instance, MYC5, collaborate in the regulation of $Y U C 8 / 9$ expression (Figure 2A,B). Extending this hypothesis, it is known that PIF4, which mediates hypocotyl elongation in response to high temperatures, can effectively bind to the G-motif located on the YUC8 promoter [53]. Furthermore, it has been reported that the jasmonate-inducible ETHYLENE RESPONSE FACTOR 109 (ERF109) physically interacts with the DNA-binding site $5^{\prime}$-GCCGCC- $3^{\prime}$ to control ASA1 and YUC2 transcript accumulation [54]. However, we were unable to identify the mentioned GCC-box motif in the promoter region of neither YUC8 nor YUC9.

Here, we demonstrated that all three described MYC proteins bind with similar, although not identical affinities to the core $5^{\prime}$-CACGTC-3' motif, called G-box, and its variants [32,55]. We analyzed the existence of these JA-responsive elements in the promoter sequence of the eleven Arabidopsis YUCCA members. Our results clearly identified a specific G-box motif configuration composed by the "tandem" 1-9-1 (5'-CACGTG-CACGTCCACGTG-3') followed by the G-box $3\left(5^{\prime}\right.$-CATGTG-3') in the region of the YUC8 and YUC9 promoters (Figure 3). We provided multiple lines of evidence, including effector-reporter assays in $N$. benthamiana and $A$. thaliana leaf protoplasts, to demonstrate that all three MYC transcription factors bind to the YUC8 and YUC9 promoters in vivo, when the 1-9-1 G-box-tandem or the 3 G-box variants are present (Figures 4, 5 and A2). Intriguingly, our experiments employing leaf protoplasts further validated that MYC2 acts as a direct regulator of YUC9 (Figure 5B).

Recently, Santamaría et al. [56] demonstrated that T. urticae infestation of Arabidopsis plants activates the MYC2 defense pathway. Taking advantage of this finding, we investigated the biological role of JA-induced IAA biosynthesis by performing a T. urticae feeding experiment. As shown in Figure 6A, the pest not only activated the AOS promoter, which is known to respond to wounding [57], but also the YUC9 promoter. Recently, Zhurov et al. [58] reported the significant induction of JA production by T. urticae feeding in Arabidopsis Col-0 plants. Moreover, a more recent publication performed in Nicotiana attenuate revealed the accumulation of auxin at the site of herbivory by Manduca sexta [59]. This localized auxin increase was accompanied by rapid activation of several YUCCA-like genes in N. attenuata. Thus, our results highlight the importance of the interconnection between JA and IAA through the modulation of YUC9 expression in plant defense responses. Moreover, the T. urticae infestation experiments showed that the auxin overproducer line, YUC9ox, exhibited reduced plant damage, $\mathrm{H}_{2} \mathrm{O}_{2}$ accumulation and cell death in comparison to similarly treated wild-type plants (Figures $6 \mathrm{~B}$ and $\mathrm{A} 3$ ). It has been demonstrated that the feeding of T. urticae on plant leaves proceeds via the insertion of their stylet between the pavement cells or through the open stoma [60]. Thus, it may be speculated that epidermal cell expansion is one reason for the observed enhanced tolerance by limiting spider mite feeding, rather than IAA-mediated immune activation. Congruent with this hypothesis, it has been demonstrated that the transient overexpression of YUC9 in N. benthamiana leaves resulted in significantly expanded pavement cells [27]. Alternatively, it is known that IAA and the biotic stress-related hormone ethylene, can interact at multiple levels [61]. For 
instance, earlier studies showed that IAA stimulates ethylene biosynthesis through the action of ACC-SYNTHASE genes (ACS) [62-66]. Likewise, Hentrich et al. [67] observed that YUC8ox and YUC9ox lines are characterized not only by the upregulation of a group of genes related to ethylene production and signaling genes, but also by elevated lignin contents relative to $\mathrm{wt}$, as shown by a qualitative phloroglucinol stain for lignin. Therefore, we suggest that the JA-IAA-ET induced lignification contributes to complicate mite feeding or reduce palatability, probably by an augmentation of the leaf rigidity and a reduction of leaf nutritional values. This hypothesis is particularly supported by the observation that the T. urticae mites actively left YUC9ox leaves, which may indicate that the spider mites completely avoid feeding on those leaves.

\section{Material and Methods}

\subsection{Plant Material}

All presented experiments used the Arabidopsis thaliana ecotype Columbia (Col-0) as genetic background (NASC stock N1092). The Arabidopsis myc mutants, i.e., myc2, $m y c 3, m y c 4, m y c 2 / m y c 3, m y c 2 / m y c 4, m y c 3 / m y c 4$, and $m y c 2 / m y c 3 / m y c 4$, the YUC9 overexpression line YUC9ox, the T-DNA insertion mutant yuc9ko, the reporter lines $p A O S:: G U S$, pYUC8::GUS and pYUC9::GUS have been previously described elsewhere [27,32,57,67]. For the sterile growth of plants, seeds were surface sterilization and then stratified at $4{ }^{\circ} \mathrm{C}$ for $48 \mathrm{~h}$ in darkness. Thereafter, the seeds were sown on solidified $\frac{1}{2}$-strength Murashige and Skoog medium supplemented with $1 \%$ sucrose. Plant growth was performed under controlled conditions $\left(22^{\circ} \mathrm{C}, 16 \mathrm{~h} \mathrm{light} / 8 \mathrm{~h}\right.$ dark and $100 \mu \mathrm{mol} / \mathrm{m}^{2} \mathrm{~s}^{1}$ light intensity). For plant defense experiments and protoplast isolation, 10-days old Arabidopsis plants were transferred to a mixture of peat and vermiculite (3:1), and further grown under the same condition described above. The transactivation assay was carried out using 14-days old $N$. benthamiana seedlings grown on peat-based soil under controlled conditions $\left(25^{\circ} \mathrm{C}\right.$ and $40-65 \%$ relative humidity, $16 \mathrm{~h}$ light/ $8 \mathrm{~h}$ dark) for 2 to 3 weeks.

\section{2. $q R T-P C R$ Analysis}

To quantify gene expression levels of YUC8 and YUC9, we incubated 10-days old Arabidopsis seedlings with either MeJA $(50 \mu \mathrm{M})$ or a control mock solution $(0.5 \%$ methanol, $v / v$ ) over $2 \mathrm{~h}$ (YUC9) or $4 \mathrm{~h}$ (YUC8) to account for the different expression strength and response characteristics of the two genes towards MeJA reported by Hentrich et al. [27]. Thereafter, total RNA was isolated from $100 \mathrm{mg}$ of whole seedlings using the phenol:chloroform method, coupled to lithium chloride precipitation, according to Box et al. [68]. The polyAmRNA was additionally purified using the Oligotex mRNA mini Kit (QIAGEN, Hilden, Germany). Purified mRNA was reverse-transcribed into complementary DNA (cDNA) employing the RNA-dependent DNA polymerase M-MLV (Promega, Madison, WI, USA) following the manufactured instructions. Quantitative RT-PCRs were carried out using a LightCycler ${ }^{\circledR} 480$ (Roche Diagnostics, Rotkreuz, Switzerland) thermocycler following the manufacturer's instructions $\left[95^{\circ} \mathrm{C}\right.$ for $10 \mathrm{~s}, 60^{\circ} \mathrm{C}$ for $20 \mathrm{~s}, 72^{\circ} \mathrm{C}$ for $\left.30 \mathrm{~s}\right] \times 45$ cycles. For data accuracy, three independent biological replicates were tested in triplicate (technical replicates). The relative gene expression levels were calculated according the $2^{-\Delta \Delta \mathrm{Ct}}$ method $[69,70]$. Primers used for analyzing mRNA levels are listed in Table A1. For data normalization we selected APT1 and UBI10 as the reference genes [71].

\subsection{Auxin Quantification}

Extraction of IAA was carried out according to Pérez-Alonso et al. [72]. In essence, approximately $100 \mathrm{mg}$ of 10 days-old seedlings were harvested and directly transferred into $1 \mathrm{~mL}$ of methanol containing $50 \mathrm{pmol}$ of the internal standard $\left[{ }^{2} \mathrm{H}_{2}\right]-\mathrm{IAA}$ (OlChemIm Ltd., Olomouc, Czech Republic). After hormone extraction, the IAA contents were examined by gas GC-MS/MS. For this, dried samples were resuspended in $20 \mu \mathrm{L}$ derivatization solution ( $88 \%$ acetone:methanol $(9: 1, v / v), 11.8 \%$ diethyl ether, $1.2 \%$ Trimethylsilyl diazomethane, $2 \mathrm{M}$ in diethyl ether). After an incubation of $30 \mathrm{~min}$ at RT, $1 \mu \mathrm{L}$ of the derivatized sample 
was injected splitless into a BRUKER Daltonics (Bremen, Germany) 451 gas chromatograph equipped with a stationary phase ZB-35 $(30 \mathrm{~m} \times 0.25 \mathrm{~mm}, 0.25 \mu \mathrm{m}$ film) fused silica capillary column (Phenomenex, Torrance, CA, USA). Helium at a flow rate of $1 \mathrm{~mL} \mathrm{~min}^{-1}$ was used as the mobile phase for the gas chromatographic separation. The injector temperature was set to $250^{\circ} \mathrm{C}$ and the column was held at $50{ }^{\circ} \mathrm{C}$ for $1.2 \mathrm{~min}$. Thereafter, the temperature was increased by $30^{\circ} \mathrm{C} \mathrm{min}-1$ to $120^{\circ} \mathrm{C}$, and finally to $325^{\circ} \mathrm{C}$ by $10^{\circ} \mathrm{C} \mathrm{min}-1$ and held there for four additional minutes. The column effluent was introduced into the ion source of a Scion-TQ triple quadrupole mass spectrometer (BRUKER Daltonics, Bremen, Germany). The transfer line and the ion source temperatures were maintained at $250{ }^{\circ} \mathrm{C}$ and $200{ }^{\circ} \mathrm{C}$, respectively. Ions were generated by a $70 \mathrm{eV}$ electron beam at an ionization current of $80 \mu \mathrm{A}$, and 30 spectra s $^{-1}$ were recorded in the mass range of 50 to $600 \mathrm{~m} / \mathrm{z}$. Under the given conditions the retention time for the endogenous methylated-IAA hormone was $13.6 \mathrm{~min}$. For quantification, we selected the following precursor ions and corresponding diagnostic product ions-MeIAA $\left(m / z\right.$ 189/130) and $\left[{ }^{2} \mathrm{H}_{2}\right]$-MeIAA $(m / z$ 191/132).

\subsection{In Silico Analysis of YUCCA Promoter Sequences}

The $3000 \mathrm{bp}$ promoter regions for all A. thaliana YUCCA genes were retrieved from the NCBI database (https:/ /www.ncbi.nlm.nih.gov/gene/, accessed on: 8 September 2021) using the corresponding gene accession numbers: At4g32450 (YUC1), At4g13260 (YUC2), At1g04610 (YUC3), At5g11320 (YUC4), At5g43890 (YUC5), At5g25620 (YUC6), At2g33230 (YUC7), At4g28720 (YUC8), At1g04180 (YUC9), At1g48910 (YUC10), At1g21430 (YUC11). MYC2 binding motifs in the YUC promoter sequences were predicted by running target sequences against known cis-regulatory elements in the AtPan collection (http:// plantpan.itps.ncku.edu.tw/, accessed on: 8 September 2021) [73] and PlantCare (http: //bioinformatics.psb.ugent.be/webtools/plantcare/html/, accessed on: 8 September 2021) [74] databases. To ensure the incorporation of all the possible G-box variants described by Fernández-Calvo et al. [32] the promoter sequences were also manually inspected.

\subsection{Transient Expression Analysis in Nicotiana Benthamiana}

The YUC8 and YUC9 promoter sequences, as well as the coding sequences from MYC2, MYC3, and MYC4 were amplified using PCR specific primers (Table A1) and introduced into the entry vector pSP-Entry1 [75]. Subsequently, $p Y U C 8 / 9:: G U S$ and 35S::MYC2/3/4 constructs were obtained by transferring the target DNA fragments into the destination vectors pMDC-163 [76] or p35S-HA-GW [77,78] by LR clonase reactions (Invitrogen I Thermo Fisher Scientific, Waltham, MA, USA). Subsequently, the A. tumefaciens-mediated transient expression experiment was performed according to Ma et al. [79]. In brief, The Agrobacterium strain C58C1, carrying the desired construct, and the Agrobacterium strain P19, carrying the suppressor of gene silencing from tomato bushy stunt virus (TBSV), were infiltrated into three to four weeks-old $N$. benthamiana plants. Three days post inoculation, the infiltrated leaves were collected and the $\beta$-glucuronidase (GUS) activity was determined by histochemical analysis as detailed by Jefferson et al. [80].

GUS expression levels were additionally quantified using a fluorometric analysis [81]. For this purpose, two leaf discs were frozen in liquid nitrogen $\left(\mathrm{N}_{2}\right)$, ground and resuspended in $150 \mu \mathrm{L}$ of GUS extraction solution [50 mM sodium phosphate buffer $\mathrm{Na}_{2} \mathrm{HPO}_{4} / \mathrm{NaH}_{2} \mathrm{PO}_{4} \mathrm{pH} 7.5,10 \mathrm{mM}$ EDTA, $0.1 \%(v / v)$ Triton $\mathrm{X}-100,0.1 \%(w / v)$ sodium lauroylsarcosinate (Sigma-Aldrich, St. Louis, MO, USA), 0.05\% ( $v / v) \beta-\mathrm{MeEtOH}$. An aliquot of $10 \mu \mathrm{L}$ was used for total protein content measurement [82] using bovine- $\gamma$-globulin as the protein standard (Bio-Rad Laboratories, Hercules, CA, USA). Whereas an aliquot of $100 \mu \mathrm{L}$ of the suspension was mixed with $100 \mu \mathrm{L}$ GUS extraction solution containing $4 \mathrm{mM}$ of 4-methylumeliferyl- $\beta$-D-glucuronide (4-MUG) (Duchefa, Haarlem, Netherlands). Samples were then incubated at $37^{\circ} \mathrm{C}$ in the dark for $10 \mathrm{~min}$. After the incubation, $100 \mu \mathrm{L}$ of the 4-MUG solution were separated and the reaction was stopped by the addition of $100 \mu \mathrm{L}$ of $200 \mathrm{mM} \mathrm{Na}_{2} \mathrm{CO}_{3}\left(\mathrm{~T}_{0}\right)$. The remaining $100 \mu \mathrm{L}$ were further incubated at $37^{\circ} \mathrm{C}$ in darkness for $1 \mathrm{~h}$ and the reaction was stopped $\left(\mathrm{T}_{60}\right)$. Then, fluorescence was registered at 
$360 \mathrm{~nm}$ excitation and $460 \mathrm{~nm}$ emission (56 gain, 10 flashes, 50\% mirror) using a TECAN Genios Pro fluorescence spectrometer (MTX Lab Systems, Vienna, VA, USA). The GUS activity was calculated as follows Equations (1) and (2):

$$
\begin{gathered}
\text { GUS - Activity }[\mathrm{pmol} / \mathrm{min}]=\frac{\Delta F / 10}{t} \\
\text { GUS Activity }=\frac{\text { GUS }- \text { Activity }}{\mathrm{mg} \text { of total protein }}
\end{gathered}
$$

where $\Delta F$ is the difference in fluorescence intensity $\mathrm{T}_{60}-\mathrm{T}_{0}, 10$ are the fluorescence units corresponding to 1 pmol of hydrolyzed 4-MUG and $t$ is incubation time. Two independent experiments were carried out and GUS activity was quantified in triplicates.

\subsection{Arabidopsis Protoplast-Based Transient Expression}

To generate the reporter plasmids $p Y U C 8:: G U S$ and $p Y U C 9:: G U S$, we amplified the promoter sequences of YUC8 and YUC9 containing different MYC2/3/4 binding sites, using PCR specific primers (able A1) and ligated them into the pGEM $^{\circledR}-\mathrm{T}$ vector (Promega, Madison, WI, USA). Thereafter, DNA fragments were digested by restriction endonucleases and cloned into the pBT-10 plasmid [83]. On the other hand, the effector plasmids 35S:MYC2/3/4 were made as described above. In this case, however, pEarlyGate-210 [84] was used as the destination vector. After construct generation, mesophyll protoplast isolation and PEG-calcium mediated DNA transfection were performed according to Mathur and Koncz [85], Yoo et al. [86], and Alonso et al. [87]. In this work, $9 \mu \mathrm{g}$ of each reporter construct and $14 \mu \mathrm{g}$ of the different effectors were utilized. Moreover, to normalize the transfection efficiency, $3 \mu \mathrm{g}$ of the 35S::neuroaminidase (NAN) plasmid [81] were used. Then, GUS transactivation was quantified by fluorometric analysis as already described. Furthermore, NAN activity was determined according to Kirby and Kavanagh [81]. To do this, from the $150 \mu \mathrm{L}$ resuspended protoplasts in GUS extraction solution a $10 \mu \mathrm{L}$ aliquot was mixed with $10 \mu \mathrm{L}$ NAN extraction solution [50 mM N $\mathrm{HPO}_{4} / \mathrm{NH}_{2} \mathrm{PO}_{4} \mathrm{pH}$ 7.0, $10 \mathrm{mM}$ EDTA, $0.1 \%(v / v)$ Triton $\mathrm{X}-100,0.1 \%(w / v)$ sodium lauroylsarcosinate] containing freshly added $0.05 \%(v / v) \beta$-MeEtOH and $1 \mathrm{mM} 2^{\prime}$-(4-methylumbelliferyl)- $\alpha$-D-N-acetylneuroaminic acid (4-MUN) (Duchefa, Haarlem, Netherlands). The protoplasts were then incubated at $37^{\circ} \mathrm{C}$ in the dark for $10 \mathrm{~min}\left(\mathrm{~T}_{0}\right)$. After the incubation, $3.3 \mu \mathrm{L}$ of the protoplast suspension was transferred to a $200 \mu \mathrm{L}$ of NAN stop solution [330 mM Na $2 \mathrm{CO}_{3}$ ]. The remaining protoplast/4-MUN solution was incubated at $37{ }^{\circ} \mathrm{C}$ in darkness for $1 \mathrm{~h}\left(\mathrm{~T}_{60}\right)$. Afterwards, the fluorescence was measured as described before. NAN activity was calculated as previously described [88] Equations (3) and (4):

$$
N A N-\text { Activity }[\mathrm{pmol} / \mathrm{min}]=\frac{\Delta F / 10}{t}
$$

where $\Delta F$ is the difference in fluorescence $\mathrm{T}_{60}-\mathrm{T}_{0}, 10$ are the fluorescence units corresponding to 1 pmol of hydrolysed 4-MUN and $t$ is the time of incubation. Normalization of the GUS-activity was performed by calculating the ratio of GUS and NAN activities, represented as relative GUS/NAN units, following the Equation (4):

$$
\frac{\text { GUS }}{N A N}-\text { Activity }=\frac{\text { GUS }- \text { Activity }}{N A N-\text { Activity }}
$$

To ensure data accuracy, GUS and NAN activities were measured in triplicates and each experiment was repeated at least twice.

\subsection{Plant-Arthropod Interactions}

Adult female T. urticae spider mites, London strain, isolated from infested bean plants, were carefully placed on the leaf surface from three to four-weeks-old $A$. thaliana plants according to Santamaría et al. [56]. The mites fed for four days in growth chambers $\left(25^{\circ} \mathrm{C}\right.$, 
$70 \%$ relative humidity and with $16 \mathrm{~h} \mathrm{light} / 8 \mathrm{~h}$ dark regime. Histochemical analyses of GUS activity were performed as described by Jefferson et al. [80]. For leaf damage quantification whole rosette of infested and control plants were scanned using a resolution of $1200 \mathrm{dpi}$. Plant damage was assessed as the total area of chlorotic spots based on scanned leaves overlaid with a grid of $0.25 \mathrm{~mm} \times 0.25 \mathrm{~mm}$ using Adobe Photoshop CS5 software (Adobe Systems, San Jose, CA, USA). For this, all grid units that showed at least $50 \%$ damaged areas were marked with a dot of defined size (52 pixels/dot). After marking all damaged areas, the histogram tool was used to quantify the number of pixels on the grid layer. Since each dot is represented by a defined number of pixels, the total number of dots can be calculated by dividing the total number of pixels by the number of pixels per dot. Finally, the total area of damage is calculated according to the following Equation (5):

$$
\text { Damage area }\left[\mathrm{mm}^{2}\right]=\text { number of dots } \times \text { unit area }
$$

The damaged area can be calculated in this way because each dot corresponds to one grid unit [89]. We assessed plant damage in five infested independent samples from each genotype. The previously described promoter of the wounding responsive ALLENE OXIDE SYNTHASE (AOS) gene fused to the GUS reporter gene (pAOS::GUS) [57] was used as a positive control in this experiment.

\subsection{Statistics}

The data were analyzed with Student's t-test when two means were compared. Statistical analyses were realized employing the STATGRAPHICS ${ }^{\circledR}$ Centurion XVI (Statpoint Technologies, INC., Warrenton, VA, USA).

Author Contributions: S.P. and M.-M.P.-A. conceived and designed the research; M.-M.P.-A., B.S.-P., P.O.-G., M.E.S., I.D. and S.P. performed the research and analyzed the data; S.P. was responsible for funding acquisition and wrote and edited the manuscript together with M.-M.P.-A. All authors have read and agreed to the published version of the manuscript.

Funding: This research was funded by the Spanish Ministry of Economy, Industry and Competitiveness (MINECO), grant number BFU2017-82826-R to S.P.

Institutional Review Board Statement: Not applicable.

Informed Consent Statement: Not applicable.

Data Availability Statement: All data supporting the findings of this study are available within the paper and its supplementary data in the appendices.

Acknowledgments: The authors thank Roberto Solano and Andrea Chini (Centro Nacional de Biotecnología, CNB-CSIC, Madrid) for kindly sharing the myc loss-of-function lines with us. In addition, the authors appreciate the thoughtful feedback and highly valuable comments by all members of the CBGP laboratories 127 and 132.

Conflicts of Interest: The authors declare no conflict of interests.

\section{Appendix A}

Method A1. Trypan Blue staining. Three to four weeks-old, infested A. thaliana leaves were harvested after four days of T. urticae feeding and stained with $5 \mathrm{~mL}$ lactophenoltrypan blue solution (10 mL lactic acid, $10 \mathrm{~mL}$ phenol, $10 \mathrm{~mL}$ glycerol, $10 \mathrm{~mL}$ tryptan blue (Sigma-Aldrich, St. Louis, MO, USA), dissolved in $10 \mathrm{~mL}$ of distilled $\mathrm{H}_{2} \mathrm{O}$ ) [90]. Before its use, the TB solution was diluted 1:2 with $100 \%$ ethanol. The solution including two leaves was then boiled for $1 \mathrm{~min}$ and distained for $30 \mathrm{~min}$ at room temperature in $2 \mathrm{~mL}$ chloral hydrate solution ( $5 \mathrm{~g}$ of chloral hydrate dissolved in $2 \mathrm{~mL}$ distilled water). After overnight decolorization, the chloral hydrate solution was removed and then $2 \mathrm{~mL} 50 \%$ glycerol were added. Leaves were then placed on a microscope slide, covered with a cover slip, and analyzed under bright-field lighting using a light stereomicroscope Leica MZ10F (Leica Microsystems, Wetzlar, Germany) at a magnification of $\times 8$ and $\times 40$, respectively. Images 
were captured using a Leica DFC 400C camera (Leica Microsystems, Wetzlar, Germany). Trypan blue staining was performed for five spider mite infested plants from each genotype and two control plants.

Method A2. DAB staining. We examined $\mathrm{H}_{2} \mathrm{O}_{2}$ accumulation in three to four A. thaliana leaves exposed to 4 days of T. urticae feeding using the 3,3'-diaminobenzidine (DAB) staining method [91]. For this purpose, two leaves were placed in a $15 \mathrm{~mL}$ Falcon tubes, covered with $5 \mathrm{~mL} \mathrm{DAB}$ solution $(0.1 \%(w / v)$ of 3,3-diaminobenzidine- $\mathrm{HCl}(\mathrm{pH} 3.8))$, vacuum infiltrated for $5 \mathrm{~min}$ and incubated overnight. After incubation, the DAB solution was supplemented with $10 \mathrm{mM}$ ascorbic acid. Then, three subsequent washing steps with $5 \mathrm{~mL}$ ethanol/acetic acid/glycerol $(v / v, 3: 1: 1)$ of $2 \mathrm{~h}$ each were performed to clear leaf tissues. Then, $2 \mathrm{~mL}$ of $50 \%$ glycerol were added. Microscopy and imaging were carried out using a light stereomicroscope Leica MZ10F (Leica Microsystems, Wetzlar, Germany), at a magnification of $\times 8$ and $\times 40$, and a Leica DFC 400C camera (Leica Microsystems, Wetzlar, Germany). For this experiment five spider mite infested plants and two control plants were used from each genotype.

\section{Appendix B}
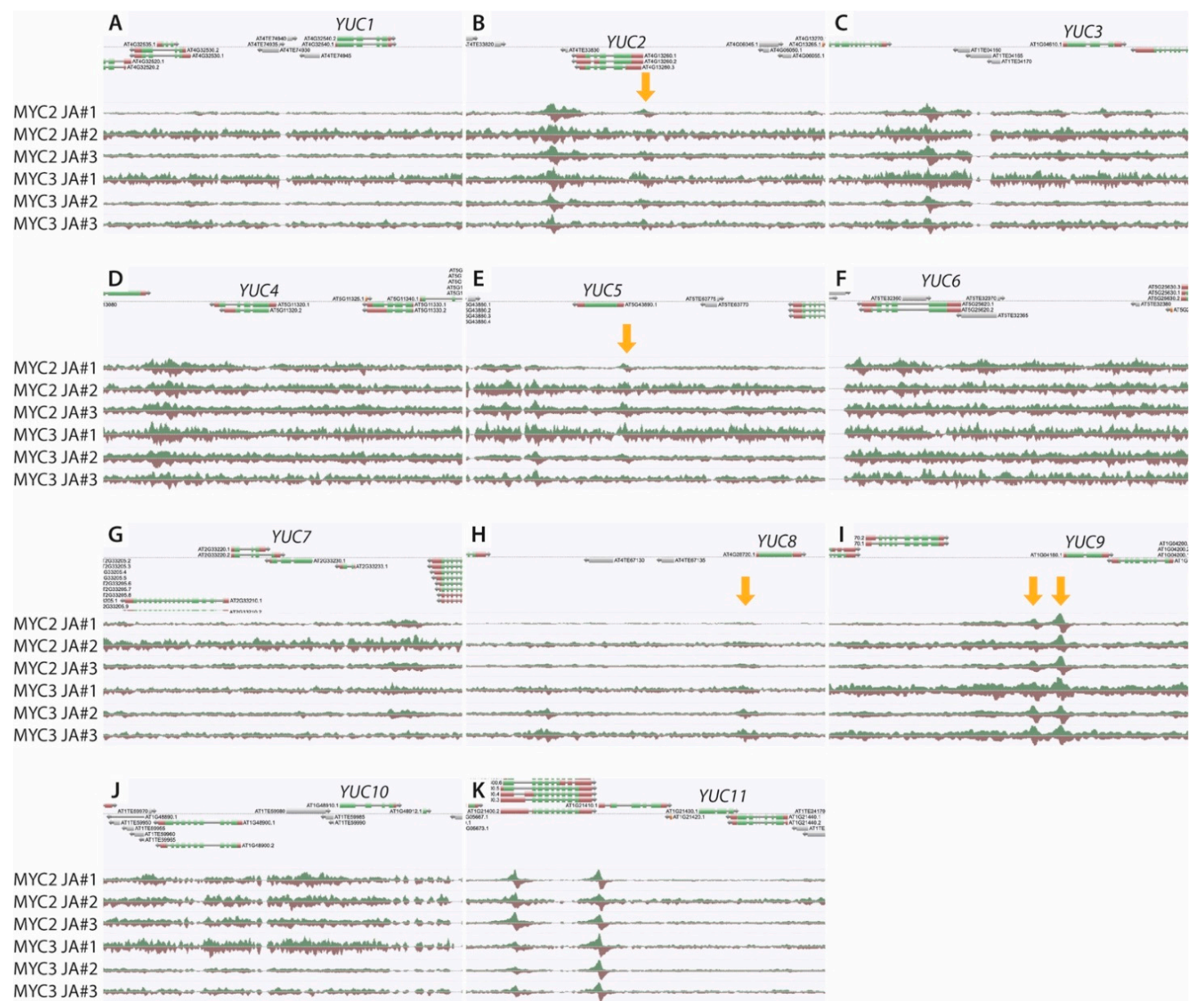

Figure A1. Genome browser screenshots showing the binding of MYC2 and MYC3 to the promoter regions of the eleven YUCCA genes. The figure shows the genomic regions around (A) YUC1, At4g32540; (B) YUC2, At4g13260; (C) YUC3, At1g04610; (D) YUC4, At5g11320; (E) YUC5, At5g43890; (F) YUC6, At5g25620; (G) YUC7, At2g33230; (H) YUC8, At4g28720; (I) YUC9, At1g04180; (J) YUC10, At1g48910; and (K) YUC11, At1g48910. The corresponding YUCCA genes are marked in each panel. Possible binding sites, represented by an enrichment of sequence reads obtained from either MYC2 or MYC3 ChIP-seq assays, in the YUC promoters are highlighted by arrows. The data have been extracted from Zander et al. [40]. Array results are available under: http:/ / neomorph.salk.edu/MYC2, last accessed: 8 September 2021. 


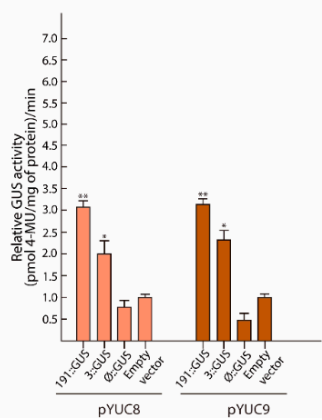

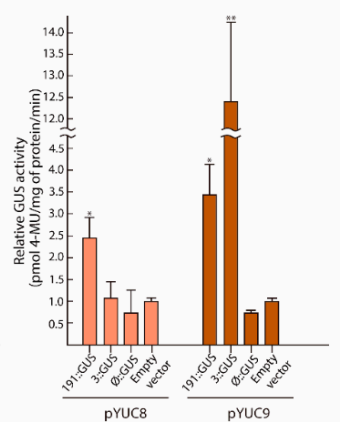

C

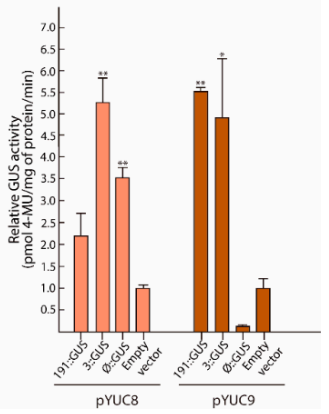

Figure A2. Relative GUS enzymatic activity in agroinfiltrated $N$. benthamiana leaves. (A) Fluororimetric GUS quantification of the -191::GUS, -3::GUS and - $6:: G U S$ reporter constructs co-transformed with the effector construct 35S::MYC2, (B) 35S::MYC3, and (C) 35S::MYC4. In this case, the empty pMDC163 vector was generated by the deletion of the $c c d B$ operon [92] and used as negative control. GUS activity was then normalized according to the empty vector, final units pmol 4-methylumelliferone (MU)/mg protein/min. Protein quantity was investigated using Bradford method [82]. Data are mean \pm SE. Three different young leaves per plant were agroinfiltrated. GUS activation of each promoter construct was quantified in triplicates. Asterisks indicate significant differences between means ${ }^{*} p<0.05,{ }^{* *} p<0.01$, Student't $t$-test comparing negative control and independent promoter constructs).

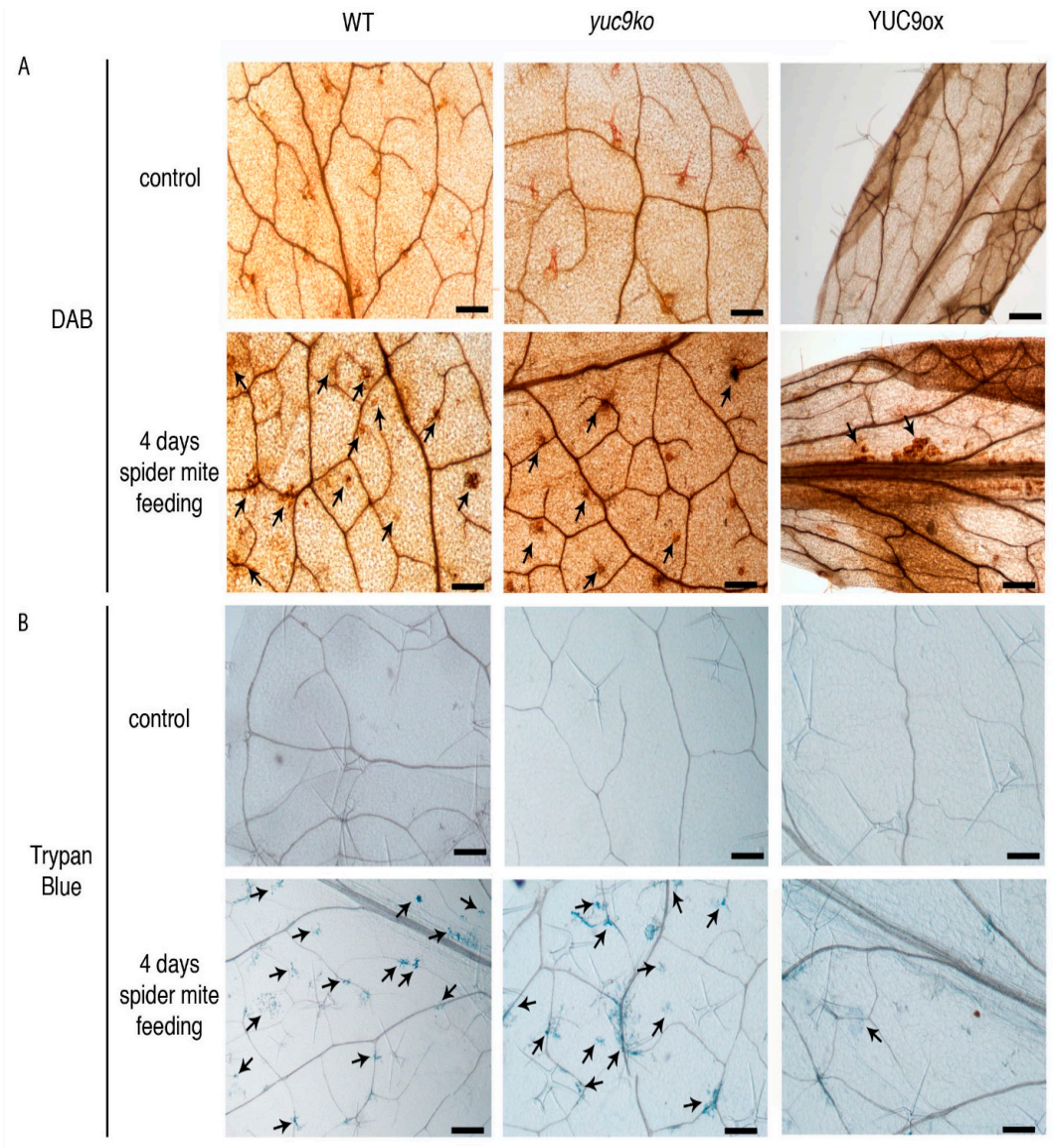

Figure A3. Histochemical analysis after spider mite herbivory. (A) DAB staining, (B) Trypan blue staining. Arrows indicate $\mathrm{H}_{2} \mathrm{O}_{2}$ accumulation and cell death, respectively. Images represent leaf details of control plants (top row) and plants exposed to 4 days spider mite feeding (bottom row). Scale bar $=1 \mathrm{~mm}$. The arrows mark tissue damages caused by mite feeding. 
Table A1. List of primers used for cloning and qRT-PCR analysis (https:/ / quantprime.mpimp-golm.mpg.de/, accessed on: 8 September 2021) [93].

\begin{tabular}{|c|c|}
\hline Primer Name & Primer Sequence $\left(5^{\prime}-3^{\prime}\right)$ and Restriction Sites \\
\hline Promoter YUC8-(919) For & TATGGATCCAAAAGTGCAGCGTCTACCAAAA \\
\hline Promoter YUC8-(919) Rev & TATTCTAGATTAGGTACGGAAAATGTGATT \\
\hline Promoter YUC8-(3) For & TATGGATCCTCCGTACCTAAAAATTGGATT \\
\hline Promoter YUC8-(3) Rev & TATTCTAGATGCTTGACGACGAAGTAATAAT \\
\hline Promoter YUC8-(Ø) For & TATGGATCCTCGTCGTCAAGCATTATCACTGTT \\
\hline Promoter YUC8-(Ø) Rev & TATCCATGGTCTAGATGGAAGTTGTATTGGAAATGGTTT \\
\hline Promoter YUC9-(919) For & TATAAGCTTAACAAAATTAGGACCCGCTCT \\
\hline Promoter YUC9-(919) Rev & TATTCTAGAGATTGAATTATATGGTAAACTCAA \\
\hline Promoter YUC9-(3) For & TATAAGCTTACCACGAAGAAAATAACATCTC \\
\hline Promoter YUC9-(3) Rev & TATCCATGGTCTAGAGTTAAGAGTTATAACGAGACTG \\
\hline Promoter YUC9-(Ø) For & TATAAGCTTCAAATTATTCACATTAATAAAATAATC \\
\hline Promoter YUC9-(Ø) Rev & TATCCATGGTCTAGATTTCTTGAGTGAGTTTTTGAATG \\
\hline ORF MYC2 For & TATGGTACCATGACTGATTACCGGCTACAACCAACGA \\
\hline ORF MYC2 Rev & TATGCGGCCGCTTAACCGATTTTTGAAATCAAACTTGCTCTGA \\
\hline ORF MYC3 For & TATGGATCCATGAACGGCACAACATCATCA \\
\hline ORF MYC3 Rev & TATGATATCTCAATAGTTTTCTCCGACTTTCGT \\
\hline ORF MYC4 For & TATGGATCCATGTCTCCGACGAATGTTCAAGTAACCGA \\
\hline ORF MYC4 Rev & TATGATATCTCATGGACATTCTCCAACTTTCTCCGTT \\
\hline pENTRY-SP1 For & TATCTGATAGTGACCTGTTCGTTGCA \\
\hline pENTRY-SP1 Rev & TATGGAGATCCGTGACGCAGTAGC \\
\hline pBT-10-Seq Rev & TATTTGGGGTTTCTACAGGACGGACCAT \\
\hline pENTRY-SP1 Rev & TATGGAGATCCGTGACGCAGTAGC \\
\hline YUC8-qPCR For & CGTCTCAAGCTTCACCTTCC \\
\hline YUC8-qPCR Rev & AGCCACTGGTCTCATCGAAC \\
\hline YUC9-qPCR For & TTCTCGCCACCGGTTATCGTAG \\
\hline YUC9-qPCR Rev & AGCGATGTTAACGGCGTCTACTG \\
\hline APT1-qPCR For & TCGTGCTGTTCCTTGCAACCG \\
\hline APT1-qPCR Rev & GCGGAGGAGAAGAGGCGGAGT \\
\hline UBI10-qPCR For & TTGGAGGATGGCAGAACTCTTGCT \\
\hline UBI10-qPCR Rev & AGTTTTCCCAGTCAACGTCTTAACGAAA \\
\hline
\end{tabular}

\section{References}

1. Kögl, F.; Erxleben, H.; Haagen-Smit, A.J. Über die Isolierung der Auxine a und b aus pflanzlichen Materialien. 9. Mitteilung über pflanzliche Wachstumsstoffe. Hoppe-Seyler's Z. Für Physiol. Chem. 1934, 225, 215-229. [CrossRef]

2. Thimann, K.V.; Koepfli, J.B. Identity of the Growth-Promoting and Root-Forming Substances of Plants. Nature 1935, 135, 101-102. [CrossRef]

3. Went, F.W. Auxin, the plant growth-hormone. Bot. Rev. 1935, 1, 162-182. [CrossRef]

4. Woodward, A.W.; Bartel, B. Auxin: Regulation, action, and interaction. Ann. Bot. 2005, 95, 707-735. [CrossRef] [PubMed]

5. Abel, S.; Theologis, A. Odyssey of auxin. Cold Spring Harb. Perspect. Biol. 2010, 2, a004572. [CrossRef] [PubMed]

6. Paponov, I.A.; Paponov, M.; Teale, W.; Menges, M.; Chakrabortee, S.; Murray, J.A.; Palme, K. Comprehensive transcriptome analysis of auxin responses in Arabidopsis. Mol. Plant 2008, 1, 321-337. [CrossRef] [PubMed]

7. McGuire, R.; Agrawal, A.A. Trade-offs between the shade-avoidance response and plant resistance to herbivores? Tests with mutant Cucumis sativus. Funct. Ecol. 2005, 19, 1025-1031. [CrossRef]

8. Walters, D.; Heil, M. Costs and trade-offs associated with induced resistance. Physiol. Mol. Plant Pathol. 2007, 71, 3-17. [CrossRef]

9. Kempel, A.; Schadler, M.; Chrobock, T.; Fischer, M.; van Kleunen, M. Tradeoffs associated with constitutive and induced plant resistance against herbivory. Proc. Natl. Acad. Sci. USA 2011, 108, 5685-5689. [CrossRef]

10. Leone, M.; Keller, M.M.; Cerrudo, I.; Ballare, C.L. To grow or defend? Low red : Far-red ratios reduce jasmonate sensitivity in Arabidopsis seedlings by promoting DELLA degradation and increasing JAZ10 stability. New Phytol. 2014, 204, 355-367. [CrossRef]

11. Huot, B.; Yao, J.; Montgomery, B.L.; He, S.Y. Growth-defense tradeoffs in plants: A balancing act to optimize fitness. Mol. Plant 2014, 7, 1267-1287. [CrossRef]

12. Kurashige, N.S.; Agrawal, A.A. Phenotypic plasticity to light competition and herbivory in Chenopodium album (Chenopodiaceae). Am. J. Bot. 2005, 92, 21-26. [CrossRef]

13. Griebel, T.; Zeier, J. Light regulation and daytime dependency of inducible plant defenses in Arabidopsis: Phytochrome signaling controls systemic acquired resistance rather than local defense. Plant Physiol. 2008, 147, 790-801. [CrossRef] 
14. Mutka, A.M.; Fawley, S.; Tsao, T.; Kunkel, B.N. Auxin promotes susceptibility to Pseudomonas syringae via a mechanism independent of suppression of salicylic acid-mediated defenses. Plant J. 2013, 74, 746-754. [CrossRef]

15. Fahlgren, N.; Montgomery, T.A.; Howell, M.D.; Allen, E.; Dvorak, S.K.; Alexander, A.L.; Carrington, J.C. Regulation of AUXIN RESPONSE FACTOR3 by TAS3 ta-siRNA affects developmental timing and patterning in Arabidopsis. Curr. Biol. 2006, 16, 939-944. [CrossRef]

16. Zhang, T.; Poudel, A.N.; Jewell, J.B.; Kitaoka, N.; Staswick, P.; Matsuura, H.; Koo, A.J. Hormone crosstalk in wound stress response: Wound-inducible amidohydrolases can simultaneously regulate jasmonate and auxin homeostasis in Arabidopsis thaliana. J. Exp. Bot. 2016, 67, 2107-2120. [CrossRef] [PubMed]

17. Sweeney, C.; Lakshmanan, V.; Bais, H.P. Interplant Aboveground Signaling Prompts Upregulation of Auxin Promoter and Malate Transporter as Part of Defensive Response in the Neighboring Plants. Front. Plant Sci. 2017, 8, 595. [CrossRef] [PubMed]

18. Böttcher, C.; Pollmann, S. Plant oxylipins: Plant responses to 12-oxo-phytodienoic acid are governed by its specific structural and functional properties. FEBS J. 2009, 276, 4693-4704. [CrossRef] [PubMed]

19. Koo, A.J.; Howe, G.A. The wound hormone jasmonate. Phytochemistry 2009, 70, 1571-1580. [CrossRef]

20. Wasternack, C.; Forner, S.; Strnad, M.; Hause, B. Jasmonates in flower and seed development. Biochimie 2013, 95, 79-85. [CrossRef] [PubMed]

21. Pérez-Alonso, M.-M.; Pollmann, S. How Auxin May Contribute to the Regulation of Plant Defense Responses against Herbivory. Austin J. Plant Biol. 2018, 4, 1-5. [CrossRef]

22. Chini, A.; Fonseca, S.; Fernandez, G.; Adie, B.; Chico, J.M.; Lorenzo, O.; Garcia-Casado, G.; Lopez-Vidriero, I.; Lozano, F.M.; Ponce, M.R.; et al. The JAZ family of repressors is the missing link in jasmonate signalling. Nature 2007, 448, 666-671. [CrossRef]

23. Kazan, K.; Manners, J.M. MYC2: The master in action. Mol. Plant 2013, 6, 686-703. [CrossRef] [PubMed]

24. Chen, Q.; Sun, J.; Zhai, Q.; Zhou, W.; Qi, L.; Xu, L.; Wang, B.; Chen, R.; Jiang, H.; Qi, J.; et al. The basic helix-loop-helix transcription factor MYC2 directly represses PLETHORA expression during jasmonate-mediated modulation of the root stem cell niche in Arabidopsis. Plant Cell 2011, 23, 3335-3352. [CrossRef] [PubMed]

25. Dombrecht, B.; Xue, G.P.; Sprague, S.J.; Kirkegaard, J.A.; Ross, J.J.; Reid, J.B.; Fitt, G.P.; Sewelam, N.; Schenk, P.M.; Manners, J.M.; et al. MYC2 differentially modulates diverse jasmonate-dependent functions in Arabidopsis. Plant Cell 2007, 19, 2225-2245. [CrossRef]

26. Sun, J.; Xu, Y.; Ye, S.; Jiang, H.; Chen, Q.; Liu, F.; Zhou, W.; Chen, R.; Li, X.; Tietz, O.; et al. Arabidopsis ASA1 is important for jasmonate-mediated regulation of auxin biosynthesis and transport during lateral root formation. Plant Cell 2009, 21, 1495-1511. [CrossRef] [PubMed]

27. Hentrich, M.; Böttcher, C.; Düchting, P.; Cheng, Y.; Zhao, Y.; Berkowitz, O.; Masle, J.; Medina, J.; Pollmann, S. The jasmonic acid signaling pathway is linked to auxin homeostasis through the modulation of YUCCA8 and YUCCA9 gene expression. Plant J. 2013, 74, 626-637. [CrossRef]

28. Cheng, Y.; Dai, X.; Zhao, Y. Auxin synthesized by the YUCCA flavin monooxygenases is essential for embryogenesis and leaf formation in Arabidopsis. Plant Cell 2007, 19, 2430-2439. [CrossRef]

29. Stepanova, A.N.; Robertson-Hoyt, J.; Yun, J.; Benavente, L.M.; Xie, D.Y.; Dolezal, K.; Schlereth, A.; Jürgens, G.; Alonso, J.M. TAA1-mediated auxin biosynthesis is essential for hormone crosstalk and plant development. Cell 2008, 133, 177-191. [CrossRef]

30. Won, C.; Shen, X.; Mashiguchi, K.; Zheng, Z.; Dai, X.; Cheng, Y.; Kasahara, H.; Kamiya, Y.; Chory, J.; Zhao, Y. Conversion of tryptophan to indole-3-acetic acid by TRYPTOPHAN AMINOTRANSFERASES OF ARABIDOPSIS and YUCCAs in Arabidopsis. Proc. Natl. Acad. Sci. USA 2011, 108, 18518-18523. [CrossRef]

31. Mano, Y.; Nemoto, K. The pathway of auxin biosynthesis in plants. J. Exp. Bot. 2012, 63, 2853-2872. [CrossRef] [PubMed]

32. Fernández-Calvo, P.; Chini, A.; Fernández-Barbero, G.; Chico, J.M.; Gimenez-lbanez, S.; Geerinck, J.; Eeckhout, D.; Schweizer, F.; Godoy, M.; Franco-Zorrilla, J.M.; et al. The Arabidopsis bHLH transcription factors MYC3 and MYC4 are targets of JAZ repressors and act additively with MYC2 in the activation of jasmonate responses. Plant Cell 2011, 23, 701-715. [CrossRef] [PubMed]

33. Liu, Z.; Li, N.; Zhang, Y.; Li, Y. Transcriptional repression of GIF1 by the KIX-PPD-MYC repressor complex controls seed size in Arabidopsis. Nat. Commun. 2020, 11, 1846. [CrossRef] [PubMed]

34. Omidbakhshfard, M.A.; Proost, S.; Fujikura, U.; Mueller-Roeber, B. Growth-Regulating Factors (GRFs): A Small Transcription Factor Family with Important Functions in Plant Biology. Mol. Plant 2015, 8, 998-1010. [CrossRef] [PubMed]

35. Liu, J.; Rice, J.H.; Chen, N.; Baum, T.J.; Hewezi, T. Synchronization of Developmental Processes and Defense Signaling by Growth Regulating Transcription Factors. PLoS ONE 2014, 9, e98477. [CrossRef] [PubMed]

36. Zhang, C.; Lei, Y.; Lu, C.; Wang, L.; Wu, J. MYC2, MYC3, and MYC4 function additively in wounding-induced jasmonic acid biosynthesis and catabolism. J. Integr. Plant Biol. 2020, 62, 1159-1175. [CrossRef] [PubMed]

37. Song, S.; Huang, H.; Wang, J.; Liu, B.; Qi, T.; Xie, D. MYC5 is Involved in Jasmonate-Regulated Plant Growth, Leaf Senescence and Defense Responses. Plant Cell Physiol. 2017, 58, 1752-1763. [CrossRef] [PubMed]

38. Van Moerkercke, A.; Duncan, O.; Zander, M.; Šimura, J.; Broda, M.; Vanden Bossche, R.; Lewsey, M.G.; Lama, S.; Singh, K.B.; Ljung, K.; et al. A MYC2/MYC3/MYC4-dependent transcription factor network regulates water spray-responsive gene expression and jasmonate levels. Proc. Natl. Acad. Sci. USA 2019, 116, 23345-23356. [CrossRef] 
39. Kiran, K.; Ansari, S.A.; Srivastava, R.; Lodhi, N.; Chaturvedi, C.P.; Sawant, S.V.; Tuli, R. The TATA-box sequence in the basal promoter contributes to determining light-dependent gene expression in plants. Plant Physiol. 2006, 142, 364-376. [CrossRef]

40. Zander, M.; Lewsey, M.G.; Clark, N.M.; Yin, L.; Bartlett, A.; Saldierna Guzmán, J.P.; Hann, E.; Langford, A.E.; Jow, B.; Wise, A.; et al. Integrated multi-omics framework of the plant response to jasmonic acid. Nat. Plants 2020, 6, 290-302. [CrossRef]

41. Turner, J.G.; Ellis, C.; Devoto, A. The jasmonate signal pathway. Plant Cell 2002, 14 (Suppl. S1), S153-S164. [CrossRef]

42. Lorenzo, O.; Chico, J.M.; Sánchez-Serrano, J.J.; Solano, R. JASMONATE-INSENSITIVE1 encodes a MYC transcription factor essential to discriminate between different jasmonate-regulated defense responses in Arabidopsis. Plant Cell 2004, 16, 1938-1950. [CrossRef] [PubMed]

43. Schweizer, F.; Fernández-Calvo, P.; Zander, M.; Diez-Diaz, M.; Fonseca, S.; Glauser, G.; Lewsey, M.G.; Ecker, J.R.; Solano, R.; Reymond, P. Arabidopsis basic helix-loop-helix transcription factors MYC2, MYC3, and MYC4 regulate glucosinolate biosynthesis, insect performance, and feeding behavior. Plant Cell 2013, 25, 3117-3132. [CrossRef] [PubMed]

44. Hoffmann, M.; Hentrich, M.; Pollmann, S. Auxin-oxylipin crosstalk: Relationship of antagonists. J. Integr. Plant Biol. 2011, 53, 429-445. [CrossRef] [PubMed]

45. Pérez, A.C.; Goossens, A. Jasmonate signalling: A copycat of auxin signalling? Plant Cell Environ. 2013, 36, 2071-2084. [CrossRef]

46. Shabek, N.; Zheng, N. Plant ubiquitin ligases as signaling hubs. Nat. Struct. Mol. Biol. 2014, 21, 293-296. [CrossRef]

47. Tiryaki, I.; Staswick, P.E. An Arabidopsis mutant defective in jasmonate response is allelic to the auxin-signaling mutant axr1. Plant Physiol. 2002, 130, 887-894. [CrossRef] [PubMed]

48. Ren, C.; Pan, J.; Peng, W.; Genschik, P.; Hobbie, L.; Hellmann, H.; Estelle, M.; Gao, B.; Peng, J.; Sun, C.; et al. Point mutations in Arabidopsis Cullin1 reveal its essential role in jasmonate response. Plant J. 2005, 42, 514-524. [CrossRef]

49. Nagpal, P.; Ellis, C.M.; Weber, H.; Ploense, S.E.; Barkawi, L.S.; Guilfoyle, T.J.; Hagen, G.; Alonso, J.M.; Cohen, J.D.; Farmer, E.E.; et al. Auxin response factors ARF6 and ARF8 promote jasmonic acid production and flower maturation. Development 2005, 132, 4107-4118. [CrossRef]

50. Gutjahr, C.; Riemann, M.; Müller, A.; Düchting, P.; Weiler, E.W.; Nick, P. Cholodny-Went revisited: A role for jasmonate in gravitropism of rice coleoptiles. Planta 2005, 222, 575-585. [CrossRef]

51. Mueller, S.; Hilbert, B.; Dueckershoff, K.; Roitsch, T.; Krischke, M.; Mueller, M.J.; Berger, S. General detoxification and stress responses are mediated by oxidized lipids through TGA transcription factors in Arabidopsis. Plant Cell 2008, 20, 768-785. [CrossRef] [PubMed]

52. Pauwels, L.; Morreel, K.; De Witte, E.; Lammertyn, F.; Van Montagu, M.; Boerjan, W.; Inze, D.; Goossens, A. Mapping methyl jasmonate-mediated transcriptional reprogramming of metabolism and cell cycle progression in cultured Arabidopsis cells. Proc. Natl. Acad. Sci. USA 2008, 105, 1380-1385. [CrossRef]

53. Sun, J.; Qi, L.; Li, Y.; Chu, J.; Li, C. PIF4-mediated activation of YUCCA8 expression integrates temperature into the auxin pathway in regulating Arabidopsis hypocotyl growth. PLoS Genet. 2012, 8, e1002594. [CrossRef] [PubMed]

54. Cai, X.T.; Xu, P.; Zhao, P.X.; Liu, R.; Yu, L.H.; Xiang, C.B. Arabidopsis ERF109 mediates cross-talk between jasmonic acid and auxin biosynthesis during lateral root formation. Nat. Commun. 2014, 5, 5833. [CrossRef] [PubMed]

55. Chini, A.; Boter, M.; Solano, R. Plant oxylipins: COI1/JAZs/MYC2 as the core jasmonic acid-signalling module. FEBS J. 2009, 276, 4682-4692. [CrossRef]

56. Santamaría, M.E.; Martínez, M.; Arnaiz, A.; Ortego, F.; Grbic, V.; Díaz, I. MATI, a Novel Protein Involved in the Regulation of Herbivore-Associated Signaling Pathways. Front. Plant Sci. 2017, 8, 975. [CrossRef] [PubMed]

57. Kubigsteltig, I.; Laudert, D.; Weiler, E.W. Structure and regulation of the Arabidopsis thaliana allene oxide synthase gene. Planta 1999, 208, 463-471. [CrossRef]

58. Zhurov, V.; Navarro, M.; Bruinsma, K.A.; Arbona, V.; Santamaría, M.E.; Cazaux, M.; Wybouw, N.; Osborne, E.J.; Ens, C.; Rioja, C.; et al. Reciprocal responses in the interaction between Arabidopsis and the cell-content-feeding chelicerate herbivore spider mite. Plant Physiol. 2014, 164, 384-399. [CrossRef] [PubMed]

59. Machado, R.A.; Robert, C.A.; Arce, C.C.; Ferrieri, A.P.; Xu, S.; Jimenez-Aleman, G.H.; Baldwin, I.T.; Erb, M. Auxin Is Rapidly Induced by Herbivore Attack and Regulates a Subset of Systemic, Jasmonate-Dependent Defenses. Plant Physiol. 2016, 172, 521-532. [CrossRef] [PubMed]

60. Bensoussan, N.; Santamaria, M.E.; Zhurov, V.; Díaz, I.; Grbic, M.; Grbic, V. Plant-Herbivore Interaction: Dissection of the Cellular Pattern of Tetranychus urticae Feeding on the Host Plant. Front. Plant Sci. 2016, 7, 1105. [CrossRef]

61. Stepanova, A.N.; Yun, J.; Likhacheva, A.V.; Alonso, J.M. Multilevel interactions between ethylene and auxin in Arabidopsis roots Plant Cell 2007, 19, 2169-2185. [CrossRef]

62. Jones, J.F.; Kende, H. Auxin-induced ethylene biosynthesis in subapical stem sections of etiolated seedlings of Pisum sativum L. Planta 1979, 146, 649-656. [CrossRef]

63. Yu, Y.B.; Adams, D.O.; Yang, S.F. Regulation of Auxin-induced Ethylene Production in Mung Bean Hypocotyls: Role of 1-Aminocyclopropane-1-Carboxylic Acid. Plant Physiol. 1979, 63, 589-590. [CrossRef] [PubMed]

64. Yang, S.F.; Hoffman, N.E. Ethylene Biosynthesis and its Regulation in Higher Plants. Annu. Rev. Plant Physiol. 1984, 35, 155-189. [CrossRef] 
65. Abel, S.; Nguyen, M.D.; Chow, W.; Theologis, A. ACS4, a primary indoleacetic acid-responsive gene encoding 1-aminocyclopropane -1carboxylate synthase in Arabidopsis thaliana. Structural characterization, expression in Escherichia coli, and expression characteristics in response to auxin. J. Biol. Chem. 1995, 270, 19093-19099. [CrossRef]

66. Tsuchisaka, A.; Yu, G.; Jin, H.; Alonso, J.M.; Ecker, J.R.; Zhang, X.; Gao, S.; Theologis, A. A combinatorial interplay among the 1-aminocyclopropane-1-carboxylate isoforms regulates ethylene biosynthesis in Arabidopsis thaliana. Genetics 2009, 183, 979-1003. [CrossRef]

67. Hentrich, M.; Sánchez-Parra, B.; Pérez-Alonso, M.M.; Carrasco-Loba, V.; Carrillo, L.; Vicente-Carbajosa, J.; Medina, J.; Pollmann, S. YUCCA8 and YUCCA9 overexpression reveals a link between auxin signaling and lignification through the induction of ethylene biosynthesis. Plant Signal. Behav. 2013, 8, e26363. [CrossRef] [PubMed]

68. Box, M.S.; Coustham, V.; Dean, C.; Mylne, J.S. Protocol: A simple phenol-based method for 96-well extraction of high quality RNA from Arabidopsis. Plant Methods 2011, 7, 7. [CrossRef] [PubMed]

69. Livak, K.J.; Schmittgen, T.D. Analysis of relative gene expression data using real-time quantitative PCR and the $2^{(-\Delta \Delta C T)}$ Method. Methods 2001, 25, 402-408. [CrossRef]

70. Schmittgen, T.D.; Livak, K.J. Analyzing real-time PCR data by the comparative $C_{\mathrm{T}}$ method. Nat. Protoc. 2008, 3, 1101-1108. [CrossRef] [PubMed]

71. Czechowski, T.; Stitt, M.; Altmann, T.; Udvardi, M.K.; Scheible, W.R. Genome-wide identification and testing of superior reference genes for transcript normalization in Arabidopsis. Plant Physiol. 2005, 139, 5-17. [CrossRef] [PubMed]

72. Pérez-Alonso, M.M.; Ortiz-García, P.; Moya-Cuevas, J.; Pollmann, S. Mass Spectrometric Monitoring of Plant Hormone Cross Talk During Biotic Stress Responses in Potato (Solanum tuberosum L.). Methods Mol. Biol. 2021, 2354, 143-154. [CrossRef]

73. Chen, Y.A.; Wen, Y.C.; Chang, W.C. AtPAN: An integrated system for reconstructing transcriptional regulatory networks in Arabidopsis thaliana. BMC Genom. 2012, 13, 85. [CrossRef]

74. Lescot, M.; Dehais, P.; Thijs, G.; Marchal, K.; Moreau, Y.; Van de Peer, Y.; Rouze, P.; Rombauts, S. PlantCARE, a database of plant cis-acting regulatory elements and a portal to tools for in silico analysis of promoter sequences. Nucleic Acids Res. 2002, 30, 325-327. [CrossRef] [PubMed]

75. Pérez-Alonso, M.M.; Ortiz-García, P.; Moya-Cuevas, J.; Lehmann, T.; Sánchez-Parra, B.; Björk, R.G.; Karim, S.; Amirjani, M.R.; Aronsson, H.; Wilkinson, M.D.; et al. Endogenous indole-3-acetamide levels contribute to the crosstalk between auxin and abscisic acid, and trigger plant stress responses in Arabidopsis thaliana. J. Exp. Bot. 2021, 72, 459-475. [CrossRef] [PubMed]

76. Curtis, M.D.; Grossniklaus, U. A gateway cloning vector set for high-throughput functional analysis of genes in planta. Plant Physiol. 2003, 133, 462-469. [CrossRef] [PubMed]

77. Ehlert, A.; Weltmeier, F.; Wang, X.; Mayer, C.S.; Smeekens, S.; Vicente-Carbajosa, J.; Droge-Laser, W. Two-hybrid protein-protein interaction analysis in Arabidopsis protoplasts: Establishment of a heterodimerization map of group C and group S bZIP transcription factors. Plant J. 2006, 46, 890-900. [CrossRef]

78. Weltmeier, F.; Ehlert, A.; Mayer, C.S.; Dietrich, K.; Wang, X.; Schutze, K.; Alonso, R.; Harter, K.; Vicente-Carbajosa, J.; Droge-Laser, W. Combinatorial control of Arabidopsis proline dehydrogenase transcription by specific heterodimerisation of bZIP transcription factors. EMBO J. 2006, 25, 3133-3143. [CrossRef] [PubMed]

79. Ma, L.; Lukasik, E.; Gawehns, F.; Takken, F.L. The use of agroinfiltration for transient expression of plant resistance and fungal effector proteins in Nicotiana benthamiana leaves. Methods Mol. Biol. 2012, 835, 61-74. [CrossRef] [PubMed]

80. Jefferson, R.A.; Kavanagh, T.A.; Bevan, M.W. GUS fusions: B-glucuronidase as a sensitive and versatile gene fusion marker in higher plants. EMBO J. 1987, 6, 3901-3907. [CrossRef]

81. Kirby, J.; Kavanagh, T.A. NAN fusions: A synthetic sialidase reporter gene as a sensitive and versatile partner for GUS. Plant J. 2002, 32, 391-400. [CrossRef] [PubMed]

82. Bradford, M.M. A rapid and sensitive method for the quantitation of microgram quantities of protein utilizing the principle of protein-dye binding. Anal. Biochem. 1976, 72, 248-254. [CrossRef]

83. Sprenger-Haussels, M.; Weisshaar, B. Transactivation properties of parsley proline-rich bZIP transcription factors. Plant J. 2000, 22, 1-8. [CrossRef] [PubMed]

84. Earley, K.W.; Haag, J.R.; Pontes, O.; Opper, K.; Juehne, T.; Song, K.; Pikaard, C.S. Gateway-compatible vectors for plant functional genomics and proteomics. Plant J. 2006, 45, 616-629. [CrossRef] [PubMed]

85. Mathur, J.; Koncz, C. PEG-mediated protoplast transformation with naked DNA. Methods Mol. Biol. 1998, 82, 267-276. [CrossRef]

86. Yoo, S.D.; Cho, Y.H.; Sheen, J. Arabidopsis mesophyll protoplasts: A versatile cell system for transient gene expression analysis. Nat. Protoc. 2007, 2, 1565-1572. [CrossRef] [PubMed]

87. Alonso, R.; Oñate-Sánchez, L.; Weltmeier, F.; Ehlert, A.; Díaz, I.; Dietrich, K.; Vicente-Carbajosa, J.; Dröge-Laser, W. A pivotal role of the basic leucine zipper transcription factor bZIP53 in the regulation of Arabidopsis seed maturation gene expression based on heterodimerization and protein complex formation. Plant Cell 2009, 21, 1747-1761. [CrossRef] [PubMed]

88. Gallagher, S.R. Quantitation of GUS Activity by Fluorometry. In GUS Protocols; Gallagher, S.R., Ed.; Academic Press: San Diego, CA, USA, 1992; pp. 47-59. [CrossRef]

89. Cazaux, M.; Navarro, M.; Bruinsma, K.A.; Zhurov, V.; Negrave, T.; Van Leeuwen, T.; Grbic, V.; Grbic, M. Application of two-spotted spider mite Tetranychus urticae for plant-pest interaction studies. J. Vis. Exp. 2014, 89, 51738. [CrossRef]

90. Koch, E.; Slusarenko, A. Arabidopsis Is Susceptible to Infection by a Downy Mildew Fungus. Plant Cell 1990, 2, 437-445. [CrossRef] 
91. Thordal-Christensen, H.; Zhang, Z.; Wei, Y.; Collinge, D.B. Subcellular Localization of $\mathrm{H}_{2} \mathrm{O}_{2}$ in Plants. $\mathrm{H}_{2} \mathrm{O}_{2}$ Accumulation in Papillae and Hypersensitive Response during the Barley-Powdery Mildew Interaction. Plant J. 1997, 11, 1187-1194. [CrossRef]

92. Miki, T.; Ae Park, J.; Nagao, K.; Murayama, N.; Horiuchi, T. Control of Segregation of Chromosomal DNA by Sex Factor F in Escherichia Coli. Mutants of DNA Gyrase Subunit A Suppress LetD (CcdB) Product Growth Inhibition. J. Mol. Biol. 1992, 225, 39-52. [CrossRef]

93. Arvidsson, S.; Kwasniewski, M.; Riano-Pachon, D.M.; Mueller-Roeber, B. QuantPrime-A Flexible Tool for Reliable HighThroughput Primer Design for Quantitative PCR. BMC Bioinform. 2008, 9, 465. [CrossRef] [PubMed] 